\title{
Korean Contributions to Agriculture, Technology, and State Formation in Japan: Archaeology and History of an Epochal Thousand Years, 400 B.C.-A.D. 600
}

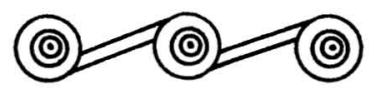

\author{
SONG-NAI RHEE, C. MELVIN AIKENS, SUNG-RAK CHOI, AND \\ HYUK-JIN RO
}

\section{INTRODUCTION}

BY 400 B.C., JAPAN WAS IN TRANSITION from its long-established Jomon hunting-fishing-gathering way of life to an agricultural economy and on the threshold of rapid growth in sociopolitical complexity. In this evolution there were four main epochs: (1) establishment of wet rice and mixed farming in the Early Yayoi by about 400 B.C.; (2) emergence of social and managerial elites during the Middle/Late Yayoi and the Early Kofun period, roughly 200 B.C.-A.D. 300; (3) growth of local military elites and power centers during the Middle Kofun period, A.D. 400-500; and (4) state formation during the Late Kofun period, A.D. 500-600. This article focuses on Korean contributions to cultural and social changes in Japan during this epoch-making thousand years of immigration, trade, and political interaction between around 400 B.C. and A.D. 600. Three broad themes are explored, supported mainly by archaeological research but also crucially illuminated by Chinese, Japanese, and Korean historical texts.

First, although connections with China have long been stressed in historical literature on Japan (Hall 1970:1-47; Reischauer and Fairbank 1958:473-497; Sansom 1962:64-174), we show that many of the agricultural, technological, and organizational skills that fostered the growth of cultural and social complexity in Japan during the Yayoi period and the formation of a centralized Yamato state in the 500s entered Japan directly from the Korea Peninsula. While local Japanese chieftains had sent several missions to China-first through the Han Chinese outposts of Lolang and Taifang on the northwest Korean frontier during the early

Song-Nai Rhee is affiliated with the Museum of Natural and Cultural History, University of Oregon, Eugene, Oregon, U.S.A. C. Melvin Aikens is a professor in the Department of Anthropology and the Museum of Natural and Cultural History, University of Oregon. Sung-rak Choi is affiliated with the Department of Archaeology, Mokp'o National University, Mokp'o, Korea. Hyuk-jin Ro is with the Department of History, Hallym University, Chuncheon, Korea. 
centuries of the Christian era and to the Song and other southern Chinese dynasties in the $400 \mathrm{~s}$ - the effect of these visits on Japanese sociocultural and technological development was negligible. Direct cultural links between Japan and China of real significance began only in the 600s, with the sending of the first cultural missions to the Sui and Tang by the Yamato court. Even in this venture, the main protagonists were Korean immigrants and their naturalized Japanese descendants (Nakamura 1981:96-97). As aptly observed within the Japanese scholarly community, "In seeking the source of Japan's ancient culture many will look to China, but the quest will finally lead to Korea, where China's advanced culture was accepted and assimilated. In actuality, the people who crossed the sea were the people of the Korea Peninsula and their culture was the Korean culture" (Kyoto Cultural Museum 1989:9).

Second, the period of intense formative interaction between Korea and Japan spanned centuries. Trade brought pottery, metals, and other goods from the peninsula to the archipelago throughout the formative period, but Korean technological skills, ideologies, and cultural systems moved with people: immigrants, traders, artisans, and in time, official envoys and allies. The initial Korean immigrants crossed the sea impelled by population growth and social tensions that were fueled by a rapid spread of agriculture in Korea. Traders and artisans followed. In later centuries, elite cadres and their retainers fled to Japan after suffering military reverses during several hundred years of nearly incessant war, as rival polities battled for political power and economic control.

Third, as Japan itself developed economically, politically, and militarily, its emerging elites began entering into political, trading, and ultimately military alliance relationships with Korean counterparts. Japanese embassies were established in southern Korea, and armies were sent to the aid of allies there. The royal court of Baekje in Korea sent artists, musicians, physicians, craftsmen, and architects to the Yamato court. It also sent scholars of Confucian classics, as well as Buddhist priests.

During Japan's Kofun period, a number of second- and third-generation Korean immigrants of previously arrived Korean elite families, now as naturalized Japanese, emerged as powerful technocrats, generals, and political officials. They provided economic strength, Korean connections, and invaluable organizational skills as bureaucrats and functionaries of the Yamato court during the process of state formation in Japan.

The main outlines of this story have long been known, but for the better part of the twentieth century, a limited archaeological record in Korea and a nationalistically based predilection in Japan to trace its connections to China rather than Korea has fostered many ambiguities and points of confusion, as implied in the above quotation and evident in Japanese as well as Western literatures on ancient Japan (Hall 1970:19-39; Kanaseki 1986:317-333; Matsushida 1997:98-99; Reischauer 1977:43-48; Sahara and Kanaseki 1981:23-26; Sansom 1962:145). More recently, however, many archaeological investigations of major scope, driven by highway, infrastructural, and urban expansion projects in both Korea and Japan, have added much new evidence. The archaeological research has also prompted intensive reconsideration of the ancient Chinese, Japanese, and Korean written sources, leading to some important reinterpretations that relate well to the archaeological record. We have found considerable scholarly consensus among 
Korean and Japanese archaeologists and historians on many significant points, though of course disagreements remain, as will be seen below.

The following account is based on an extensive review of the literature, as well as many conversations with eminent Korean and Japanese researchers during a recent month-long "archaeologists' holiday," which the authors spent visiting sites, museums, research institutes, and universities from Seoul to Kyoto.

In the following we present our evidence chronologically, according to the currently established archaeological framework. Each segment begins with a set of connected Korean developments and follows with corresponding Japanese material (Table 1). It is important to emphasize that our purpose in this article is to illuminate Korean contributions to Japanese culture, and thus we give only passing notice to Japanese elements that crossed into Korea. There certainly were such elements, reflective of the trading and political interactions mentioned above, but a systematic treatment of Japanese impingement on Korean culture would require a paper of its own and is not attempted here.

Table i. Chronological Development of Ancient China, Korea, and Japan

\begin{tabular}{|c|c|c|c|}
\hline DATE & CHINA & KOREA & JAPAN \\
\hline $\begin{array}{l}\text { B.C. } \\
10,000 \\
9000\end{array}$ & PALAEOLITHIC & PALAEOLITHIC & $\begin{array}{l}\text { PALAEOLITHIC } \\
\text { JOMON } \\
\text { Incipient } \\
\text { Initial }\end{array}$ \\
\hline $\begin{array}{l}8000 \\
7000 \\
6000\end{array}$ & $\begin{array}{l}\text { NEOLITHIC } \\
\text { Yangshao }\end{array}$ & NEOLITHIC (Cheulmun) & \\
\hline $\begin{array}{l}5000 \\
4000\end{array}$ & & & Early \\
\hline 3000 & Longshan & & Middle \\
\hline $\begin{array}{l}2000 \\
1000\end{array}$ & $\begin{array}{l}\text { SHANG } \\
\text { W. ZHOU }\end{array}$ & BRONZE AGE (Mumun) & $\begin{array}{l}\text { Late } \\
\text { Final }\end{array}$ \\
\hline $\begin{array}{l}900 \\
800\end{array}$ & & Early & \\
\hline $\begin{array}{l}700 \\
600 \\
500\end{array}$ & E. ZHOU & Middle & \\
\hline $\begin{array}{l}400 \\
300\end{array}$ & WARRING STATES & $\begin{array}{l}\text { Late } \\
\text { IRON AGE }\end{array}$ & $\begin{array}{l}\text { YAYOI } \\
\text { Early }\end{array}$ \\
\hline $\begin{array}{l}200 \\
100\end{array}$ & QIN/W. HAN & $\begin{array}{l}\text { Go Joseon } \\
\text { PROTO-THREE }\end{array}$ & Middle \\
\hline 0 & E. HAN & KINGDOMS (Samhan)/Lolang & \\
\hline $\begin{array}{l}\text { A.D. } 100 \\
200\end{array}$ & THREE KINGDOMS & KOGURYO/Taifang & $\begin{array}{l}\text { Late } \\
\text { KOFUN }\end{array}$ \\
\hline 300 & $(222-280)$ & BAEKJE/SHILLA (200-668) & Early \\
\hline $\begin{array}{l}400 \\
500\end{array}$ & $\begin{array}{l}\text { SIX DYNASTIES } \\
\quad(420-581)\end{array}$ & KAYA $(300-562)$ & $\begin{array}{l}\text { Middle } \\
\text { Late }\end{array}$ \\
\hline $\begin{array}{l}600 \\
700\end{array}$ & $\begin{array}{l}\text { SUI }(581-618) \\
\text { TANG }(618-966)\end{array}$ & UNIFIED SHILLA (668-918) & $\begin{array}{l}\text { ASUKA } \\
\text { HEIIO (Nara) }\end{array}$ \\
\hline $\begin{array}{l}800 \\
900\end{array}$ & & & $\begin{array}{l}\text { HEIAN (Kyoto) } \\
(794-857)\end{array}$ \\
\hline
\end{tabular}




\section{EMERGENCE OF AGRICULTURAL SOCIETY IN KOREA AND JAPAN}

In this section, first we present an archaeological synthesis on an emerging agricultural society during Korea's prehistoric Mumun Pottery period (c. 1500-400 B.C.) (Rhee $2001: 256-271$ ) as a backdrop for the same in Japan. We then present an archaeological synthesis on the emergence of an agricultural society of the Yayoi period under the influence of Mumun Korea.

\section{Mumun Period Korea: Rice and Mixed Farming, 1500-400 B.C.}

Millets of Panicum crusgalli and Setaria italica type have been recovered from Cheulmun Pottery period sites in northwestern Korea at Jitapni and Gungsan, dated as early as 3500 B.C. (Ahn 1998:395-405; Nelson 1993:99). By 1500 B.C., in the Early Mumun Pottery period, beans, peas, and sorghum were also grown, and by 1000 B.C. Koreans were cultivating rice in various regions throughout the peninsula (Fig. 1). At Namgyeong, near Pyeongyang, traces of carbonized rice, foxtail millet, Chinese millet, sorghum, and beans have all been dated to about 1000 B.c., and at one locality the rice remains were identifiable as being of the short-grained Oryza japonica type (Kim and Seok 1984:191-202). At Hunam-ni, in west-central Korea, carbonized grains of japonica rice, foxtail millet, barley, and sorghum have been dated to about 1000-900 в.C. (Im 1978). Shindae-dong and Baekseok-dong in south-central Korea have also yielded carbonized rice remains for the same period (Lee et al. 1998:101-103; Seong 1997:205-236). Rice, wheat, barley, and millet were all cultivated during this period by people of the Songguk-ni Culture at the site of Daepyeong-ni in the southeast (Jinju National Museum 2002:58-59). Additionally, imprints of rice remains on pottery sherds are known from Misari in west-central Korea, and plant opal traces of rice are known both there and at Okhyeon (Ahn 2000:51-52; Cho 2000:8; Jinju National Museum 2002:57-63, 142-143).

From Middle Mumun Pottery period sites dated c. 700-400 B.c., carbonized rice remains are known from Songguk-ni and Majeon-ni, both in southwest Korea. Songguk-ni, a very extensive site with many occupied areas, has yielded some $395 \mathrm{~g}$ of carbonized japonica rice and radiocarbon dates of 2665 and 2565 B.P. Majeon-ni also revealed a paddy field, irrigation channel, water control dikes, and a reservoir (Gongju National Museum 2002:4-42). Another site in the same region where paddy rice fields and irrigation channels have come to light is Gwanchang-ni (K-H. Kim and J-J. Kim 2001 :525-533). In southeastern Korea, Okhyeon gives evidence of paddy fields, irrigation channels and dikes, and human footprints in dried mud (H-S. Lee 1999:65). It is also important to note that while the evidence of rice cultivation is most impressive, Mumun period settlements sites also yield, along with rice, a range of cultigens including wheat, barley, foxtail millet, Chinese millet, beans, peas, and perilla (Ahn 1998:28; Jinju National Museum 2002:58-59).

\section{Pottery Style Zones, Working Tools, and Residential Patterns of Mumun Period Farmers, $1500-400$ B.C.}

Mumun pottery (Fig. 2) throughout Korea exhibited similar vessel forms, including globular pots, wide-mouthed jars, and dishes mounted on a base, but varia- 


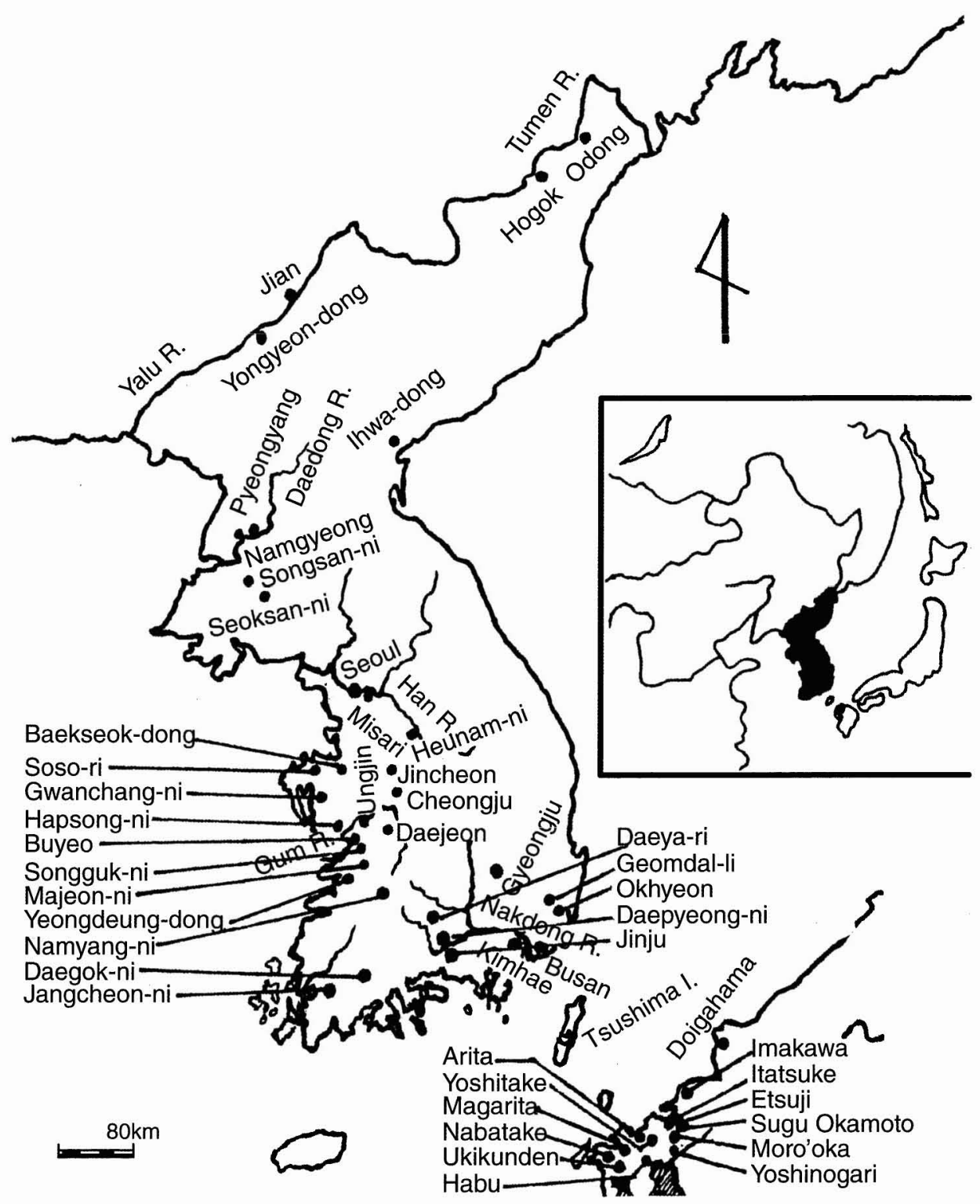

Fig. 1. Archaeological sites of Korea and northern Kyushu cited.

tions in proportions, fineness of clay, neck and rim treatment, and burnishing allow archaeologists to distinguish at least six different pottery traditions. Type distributions indicate regional foci of intercommunication and exchange that persisted throughout the Mumun period, though some pottery traditions came to spread over much greater areas than others. The six pottery zones included Paeng'i-hyeong in the northwest, Tumen-Hamgyeong in the northeast, Yeoksam-dong and Karak-dong in the southern interior, Gongyeol-mun in 
Songguk-ni red-burnished pot
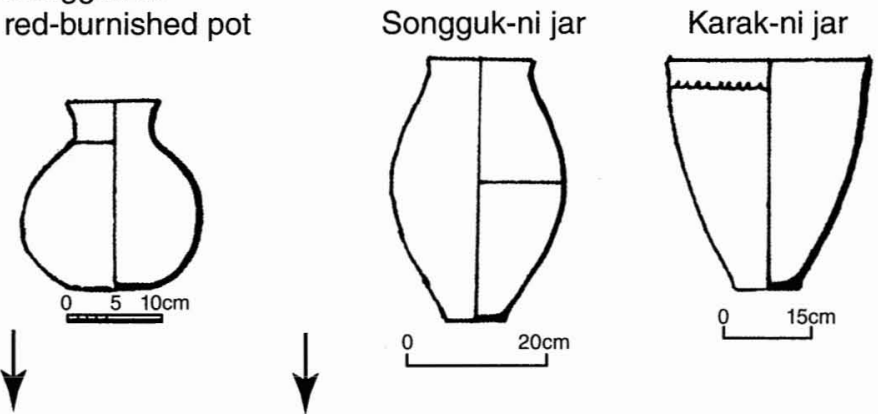

Gongyeolmun jar

Early Yayoi pots and jars
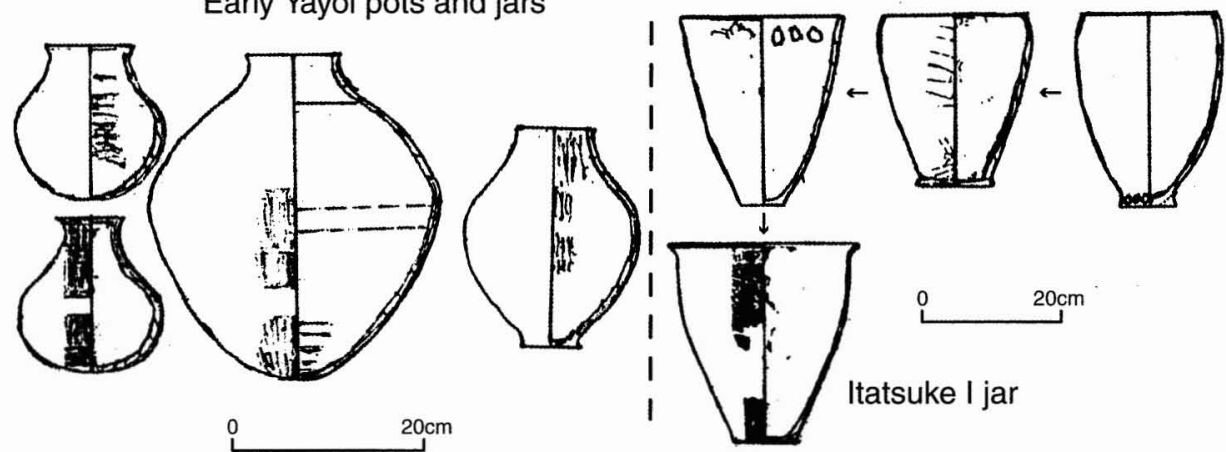

Fig. 2. Top: Mumun pottery of southern Korea (after M-Y. Song 2001:83); bottom: Early Yayoi pottery showing influence from the Mumun pottery (after Harunari 1990:34, 39).

southeastern and south-central Korea, Kakmok Doldae-mun, originally in the north but spreading southward over time, and Songguk-ni, predominantly in the southwest (Ahn 2000:44-48; W-Y. Kim 1986:70-80; C-K. Lee 1988:37-92; National Museum of Korea $1993: 26-55 ;$ M-Y. Song $2001: 83$ ).

Mumun communities across Korea shared the same basic kit of ground (polished) stone tool types of everyday use, which included reaping knives, axes, adzes, planers, chisels, daggers that resemble cast metal items, stemmed arrow points, and spindle whorls (Fig. 3). As with pottery, the form and style of these artifacts varied regionally. Ground stone tools unique to the Korea Peninsula included grooved adzes, triangular reaping knives, polished stone daggers, and elongated willow leaf-shaped arrowheads.

Residential patterns also showed fundamental similarities throughout the peninsula, with some regional variations. In the northeast and northwest, Mumun people occupied sedentary villages located along the banks of rivers or on hillsides adjacent to plains. Settlements consisted of groups of semisubterranean houses of square or rectangular plan, with a hearth located either centrally or on one side (H-D. Shin 1993:48-53). In the south, earlier people of the Doldae-mun Pottery tradition built semisubterranean houses with rectangular or narrow rectangular floor plans, but they later adopted the patterns of the neighboring Songguk-ni Culture (Jinju National Museum 2002:32). In west-central and southern Korea, 

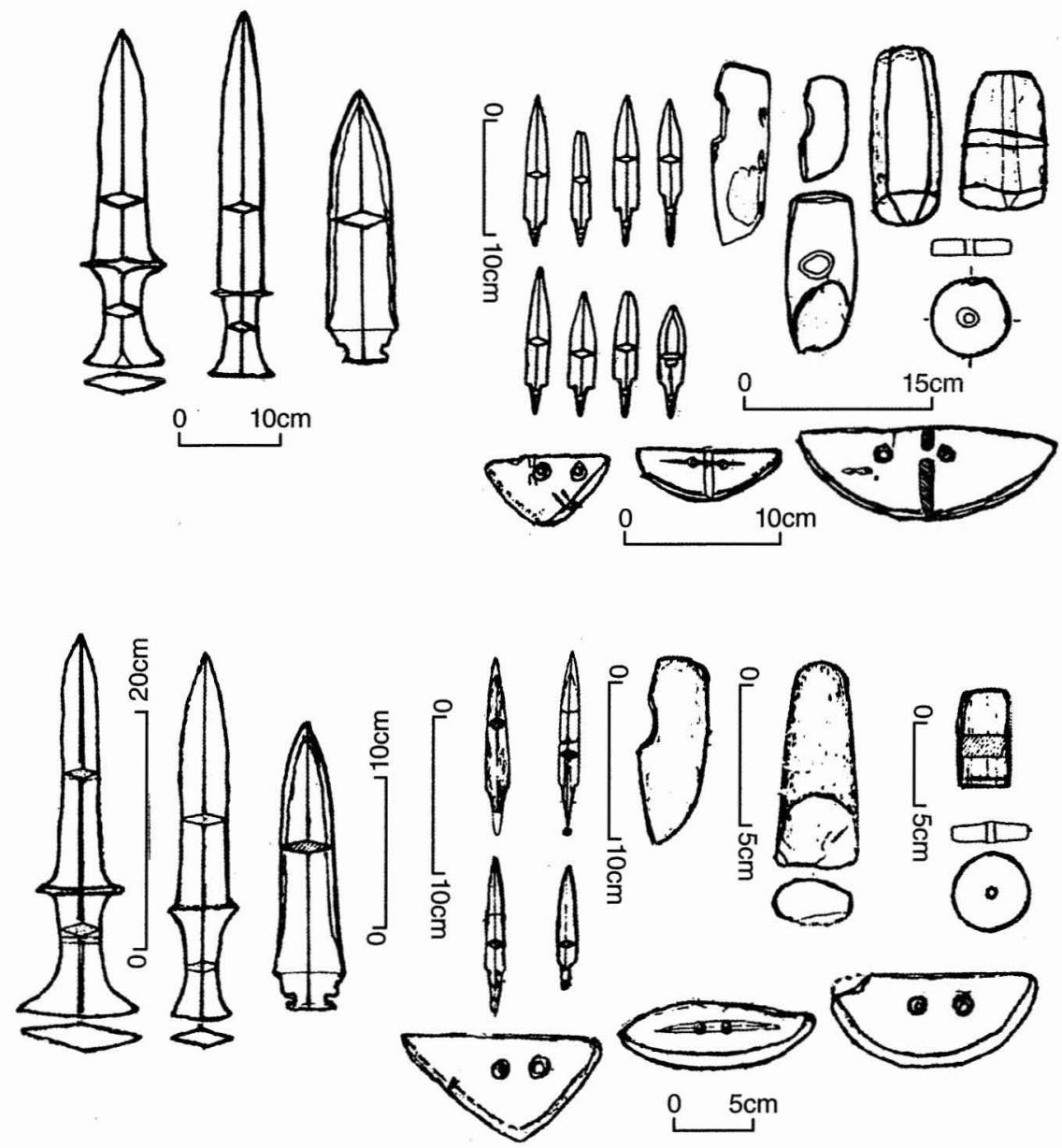

Fig. 3. Top: Mumun period stone tools of southern Korea (after Y-R. Jeon 1987:202; Lee 1993 : 420-442); bottom: stone tools from Early Yayoi sites in northern Kyushu (after Oda and Han 1991: 160-167).

people of the Songguk-ni Culture built village clusters along the banks of rivers or on low hillsides adjacent to fertile plains, in the same pattern known farther north. Their pit houses were of square, rectangular, or circular floor plan, and one of their distinguishing marks was an oval pit dug at the center of the floor with postholes placed either inside or outside the pit (National Museum of Korea 1979:110-114; Weonkwang University 2000:338-350, Fig. 4). The circular pit houses, in particular, are known as "Songguk-ni type," and during the latter part of the Mumun period, southern Korea was saturated with the Songguk-ni-type dwellings.

Large above-ground storage buildings supported on posts were also prominent in Songguk-ni-type settlements. At the Yeongdeung-dong site on Korea's southwest coastal plain, five such buildings were grouped in an open space surrounded 


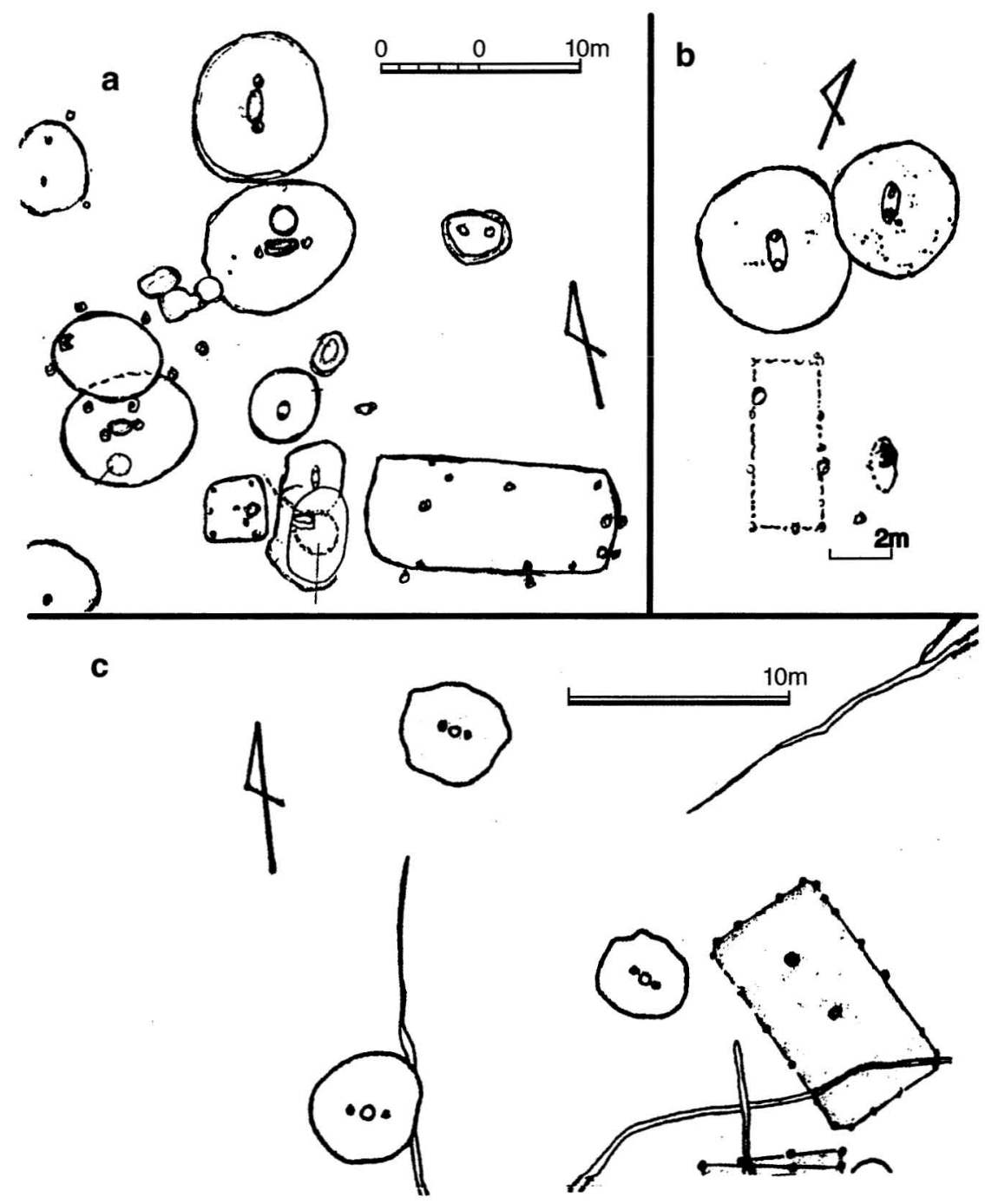

Fig. 4. Songguk-ni-type settlements: a. Daeya-ri in southern Korea (Dongui Univ. Museum 1988: 45); b. Jangcheon-ni in southwest Korea (S-R. Choi 1986:56); c. Etsuji in Fukuoka, northern Kyushu (Itatsuke City Education Committee 1995:69).

by residential structures (Weonkwang University 2000:349-350). At Jangcheonni, another coastal plain site also in southwest Korea, one such storage building was found among 12 residences (S-R. Choi 1986:35-36, 48) (Fig. 4). In the south, evidence from the partially excavated site of Daepyeong-ni suggested that one of these large storage buildings was present for every four or five dwellings (Jinju National Museum 2002:32). Clearly, Songguk-ni-type settlements produced substantial harvests of rice and other crops that were cared for on a communal basis. 


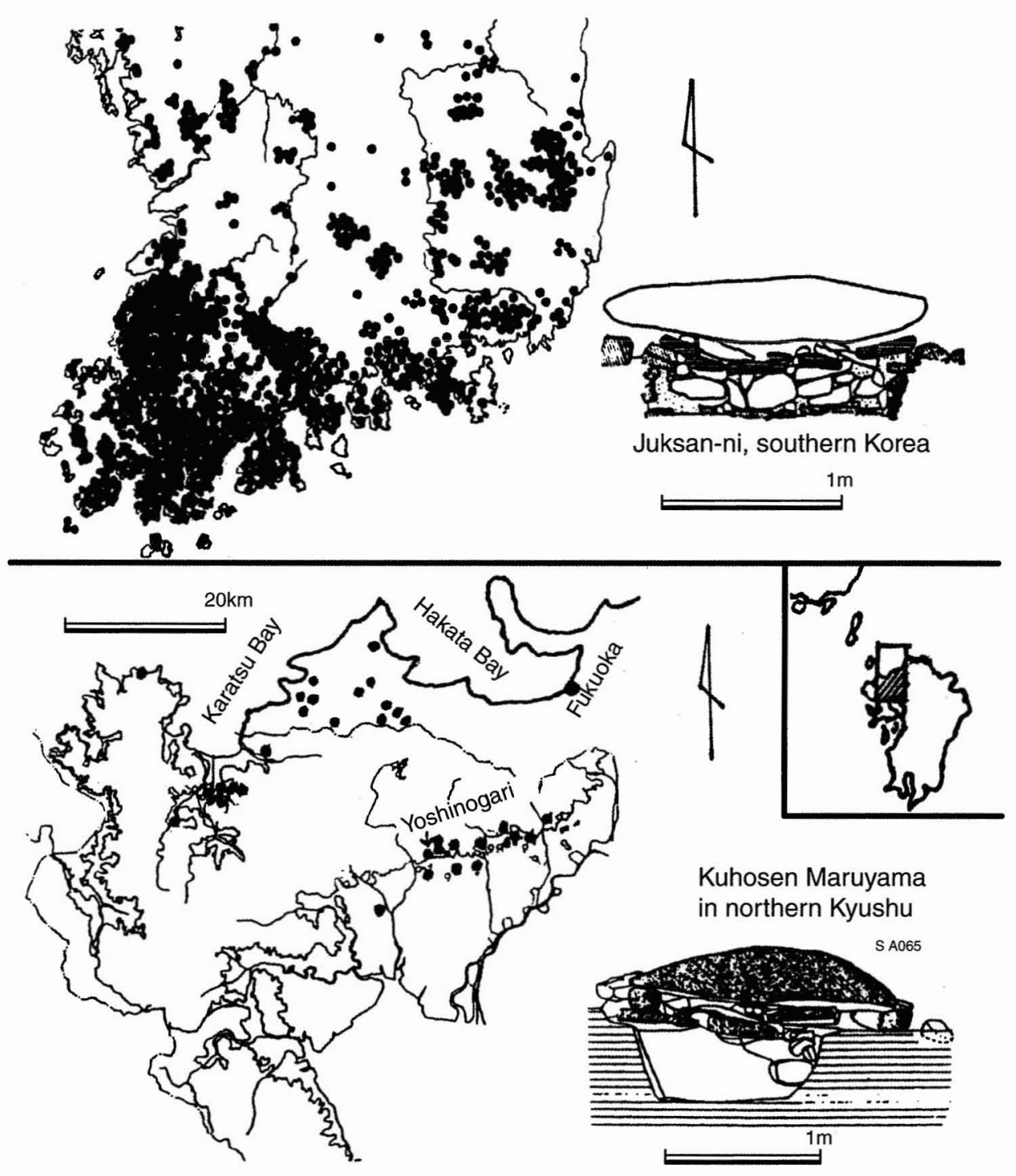

Fig. 5. Distributions of dolmens, including one of distinctive Kibanshik ( $g \circ$ table) type in southern Korea and northern Kyushu (after Y. M. Lee 1993:418; Nishitani 1997:27, 57, 73, 82).

\section{Burial Practices, Bronzes, and Bronze Technology}

The burial practices of Mumun people are the subject of a large literature, as tens of thousands of dolmen burial sites are known from this period throughout Korea. More than 19,000 dolmens have been identified in southwest Korea's South Jeolla Province alone (Mokp'o National University 1996:515) (Fig. 5). Most dolmens are very small and lack grave goods, and their sheer numbers show them to be the graves of ordinary people-perhaps family or lineage heads. A few, however, are impressively large, and both their scale and contained goods show them to be the graves of high-status individuals (Y-M. Lee 2002:346-357: Rhee 
and Choi 1992:72-77). Other burial types are also known throughout the country, including stone cists, slab-covered pit graves, and jar burials (Rhee and Choi 1992:63-72). These are far less common than dolmen graves, but stone cist graves such as those of Songguk-ni contained the most impressive items, including bronze and polished stone daggers and arrowheads, other bronze items, or tubular beads of semiprecious stone (S-O. Kim 2001:45-74; Rhee and Choi 1992:64-65).

Bronze artifacts first appeared in Korea between 800 and 700 B.C., during the Early Mumun period (National Museum of Korea and Gwangju National Museum 1992:126-132). Their forms link them to bronzes from southwestern Manchuria's Liaoning Peninsula that were distinctly different in origin, typology, and usage from the bronzes of contemporary China. In Chinese bronze assemblages, ritual vessels predominated, while the Liaoning bronze repertoire emphasized daggers, spears, arrowheads, chisels, and fan-shaped adzes. The Liaoning daggers are referred to as "bipa-shaped" in Korea for their resemblance to the hourglass-shaped traditional musical instrument (biwa in Japanese) (Rhee and Choi 1992:62). These bipa-shaped daggers are a marker for Korea's Early Bronze Age, while Korean slender bronze daggers mark its Late Bronze Age. Notably, many of the bipa-shaped daggers of the Korea Peninsula have a notched tang that sets them apart from similar daggers found in the Liaoning region of Manchuria. This characteristic and the finding of bronze casting molds cut from stone at Songguk-ni and other sites throughout the peninsula have convinced scholars that Mumun period Koreans had the technical skills to make their own bronzes (Y-M. Lee 1998:63-104). Thus far, over 100 Liaoning-type bronze artifacts have been reported from Korea, 58 of them bipa-shaped bronze daggers. The rest are spears (13), arrowheads (13), and fan-shaped adzes (10) (Y-M. Lee 1998:63).

Conspicuously, the early Korean bronze artifacts virtually all represent weaponry. They were evidently owned by high-status individuals and are found buried in their dolmen or stone cist graves along with polished stone daggers and arrowheads, tubular beads cut from semiprecious stone, and red-burnished pottery vessels. Polished stone daggers with stepped handles, apparent imitations of bronze daggers, have also been found. Bronzes were also buried for other purposes. Hoards of bronze weapons have been found in nonmortuary situations, typically in remote spots overlooking a river or the sea. It is speculated that they were ritual offerings made in times of war, plague, or natural disaster, or in some cases for the ritual protection of water-borne voyagers (S-K. Lee 2000:23-55).

\section{Agriculture and Growing Social Complexity in Mumun-Period Korea}

Korean population and settlement size grew rapidly with the support of mixed farming and paddy field agriculture. At Baekseok-dong in west-central Korea, some 82 dwellings have been dated between about 800 and 600 B.C. At Gwanchang-ni, on the west-central coast, more than 100 dwellings of the same period have been excavated. At the very extensive and only partially excavated site of Songguk-ni, 42 dwellings dating about 700-600 B.c. were uncovered within an area of only $82 \mathrm{~m}^{2}$. At Okhyeon, a Mumun village of comparable age in the southeast, more than 60 dwellings have come to light. 
Even more impressively, the extensively excavated site of Daepyeong-ni, near the southern coast, has given evidence of more than 380 dwellings dated between about 600 and 400 B.C. On adjacent riverine soil, some $40,000 \mathrm{~m}^{2}$ of cultivated fields have been identified by excavation, and the area examined is only a small proportion of the nearby land suitable for farming. Within the settlement were excavated potter's houses where various types of vessels were produced, workshops that made jewels and ornaments of semiprecious amazonite, and a stonecutter's workshop where a variety of polished stone tools were made. Clearly, Daepyeong-ni was not simply a local farming village but well on its way to becoming a regional center (Jinju National Museum 2002:143-145). Songguk-ni, where only a few of the many observed site clusters have yet been excavated, was at least comparably large and complex.

The differentiation of Mumun society proceeded hand in hand with population and settlement growth, and the co-occurrence of community storage facilities and growing elite power suggest that elite management and profit taking were at work in the continuing expansion of agricultural productivity. Craft specializations have already been mentioned, and high-status burials became more elaborate. In northern Korea, some huge megaliths were constructed for elite burials, and bipa-shaped bronze daggers were placed in stone cist burials along with polished stone daggers and arrowheads. In southern Korea as well, megalithic constructions and precious goods in burials signify social differentiation (Nelson 1993:154-155; Rhee and Choi 1992:72-77). A cist burial at Songgukni yielded a bipa-shaped dagger, a bronze chisel, a polished stone dagger, 11 arrowheads, 2 curved jewels, and 17 tubular amazonite beads. For the first time in prehistoric Korea, daggers and curved jewels appeared together as symbols of power.

Finally, strong indicators of major social divisions and potential internal stresses are the elite residential precincts and fortification systems that began to appear in some places soon after 700 B.C. (Ahn 2000:54-56, 2004:1-24; Busan University 1995:288, 295; M-Y. Song 2001:99-105). Moats have been found within the sites of Bangki-ri and Geomdal-li on the southwest coast, Sawol-li, Namsan, and Deokcheon on the south coast, and Daepyeong-ni and Songguk-ni in the southcentral region. Generally the moats did not encircle entire settlements but only particular sections within a settlement. It has been suggested that perhaps the moats were as much symbolic as military, but they apparently did serve to set off special precincts or elite members of the community and to sequester harvested grains and other communal wealth (Busan University 1995; U-D. Jeong 2000: 97-137).

But further evidence for social conflict and warfare is also clearly present in the Mumun period. Along with moat construction, there is notable evidence of violent fires in Mumun settlements. In southern Korea such evidence comes from 26 percent of all excavated structures of the Early Mumun period and 35 percent of all excavated structures of both the Middle and Late Mumun periods. The percentage was much higher in northern Korea, where up to 93.5 percent of Mumun houses excavated in the Pyeonyang area were subjected to violent conflagration. At Songguk-ni, one of the largest Middle Mumun settlements in southern Korea, the majority of square pit houses were burned violently, along with wooden barricades surrounding them, while only a small number of circular pit houses, spatially set apart from the square ones, suffered such fires (K-S. Kim 
1994:179-180). The same author has also noted a conspicuous contrast between square and circular pit houses at Songguk-ni in terms of the degree of destruction by fire they suffered and suggests that social divisions and conflicts existed within the Songguk-ni society. Based on the accumulated evidence, M-Y. Song (2000:142-144) has posited that the continual increase in Mumun population and its growing social complexity resulted in a scarcity of land and other vital resources and thus inevitably in social conflict and warfare.

\section{Final Jomon/Early Yayoi Farming Communities in Japan}

It has been suggested that in the Late Jomon period, c. 1500-1000 B.c., dry-field grain cultivation, including rice, wheat, and millet, was tried in western Japan under the influence of Korean Late Neolithic or Early Mumun mixed crop farming culture (Hirose 1997:30-48; Nishitani 2001:261-263). However, none of the Late Jomon food-producing effort left any significant impact on Jomon sociocultural and economic organizations (Hirose 1997:48-51). Nor did it have any positive impact on Jomon demography. To the contrary, for the entire Japanese archipelago, Jomon population had drastically declined from 260,000 during the Middle Jomon to 75,000 during the Final Jomon (Hanihara 1993:16), and on Kyushu Island there were only about 10,000 people (Hanihara 1984:140). Furthermore, there is no archaeological evidence for any Late Jomon agricultural activities in the plains of northern Kyushu, where Yayoi Culture first emerged. Economically, the coastal population of Kyushu was heavily dependent on marine resources (Chisholm et al. 1992:69-73) in the pre-Yayoi period. It was the appearance of paddy rice cultivation, in a fully developed form and in a relatively short time, that brought about "epochal" and "revolutionary" sociocultural changes during the Yayoi period (Harunari 1990:127-141; Hirose 1997:50-51; Osaka Yayoi Cultural Museum 1999:64; Sahara and Kanaseki 1981 :23; Shimojo 1989:2-3).

In Kyushu, where Japan's earliest paddy rice farming appears, the key periods, conventionally labeled Final Jomon and Early Yayoi, are conflated. The first evidence of paddy rice cultivation is found in sites that commonly contain both Yusu pottery, assigned to Final Jomon, and Itatsuke I pottery, assigned to Early Yayoi. Those who focus on Jomon cultural continuity call the period Final Jomon, while those who focus on the emergence of agriculture in Japan call it Early Yayoi. We adopt the tendency of recent years to treat Yusu pottery as a component of Early Yayoi (Takesue 2002:26-27; see also Harunari 1990:7). A further ambiguity in the chronological situation is that Japanese archaeologists have long assigned Early Yayoi a beginning date of about 300 B.C., reasoning from findings made long ago in Kyushu of historically dated Chinese bronze mirrors buried in Middle Yayoi pots (Aikens and Higuchi 1982:190-191). Recent accelerator mass spectrometry (AMS) radiocarbon assays on carbonized organic residues attached to Yayoi pottery suggest, however, that rice cultivation may have begun in Kyushu as long ago as 935-915 B.C. (National Museum of Japanese History 2004:18-21). Presently, however, serious questions are being raised about the archaeological associations of these dates-notably the iron tools associated with the earliest rice cultivating activities (Nishitani 2004:82-87). There are other issues being debated as well and, pending their resolution, we have 
adopted in this article a conservative lengthening of the traditional chronology, which places the beginning of paddy rice cultivation in northern Kyushu between 400 and 500 B.C. (Osaka Yayoi Culture Museum 1999:6-10).

The earliest evidences for paddy rice farming in Japan are found in the fertile plains around Hakata and Karatsu Bays in northern Kyushu (the sites discussed here are located on Fig. 1). At Itatsuke, within the present boundaries of Fukuoka City, various excavations beginning in 1951 have revealed irrigation channels, water reservation ponds, and paddy fields that were divided by boundary ridges into small sections. More than a hundred human footprints have been recorded from the dried mud of these fields. Rice grain imprints were found on sherds of Yusu and Itatsuke I pottery, as well as some carbonized specimens of shortgrained japonica rice. Preserved by waterlogged soils were also wooden hoes, unfinished wooden rakes, and spindle whorls, found along with lithic adzes, planing knives, triangular reaping knives (ishibocho), sickles, axes, willow leaf-shaped tanged arrowheads, and polished stone daggers of Mumun Korean origin (see Fig. 3). An Early Yayoi village with both inner and outer moats has been identified near the fields, as have numerous sherds of Yusu-type jars, pots, bowls, mounted dishes, and a large burnished-red pot of the Itatsuke I type (Itatsuke City Education Committee 1995:15-39; T. Mori 1985:48-55; Oda 1986:143145; Yamazaki 1991:21-22).

At Arita, also in Fukuoka City, a partially excavated semisubterranean house yielded numerous carbonized grains of japonica rice. Yusu and Itatsuke I jars, pots, and bowls were common, most of the pots being of the burnished-red Itatsuke I type. As at Itatsuke, lithic tools included polished triangular reaping knives, grooved adzes, axes, planing knives, stemmed willow leaf-shaped arrowheads, and polished stone daggers with handles of Korean type. Spindle whorls and chipped stone tools of Jomon types were also found (Oda 1986:145-146).

At Imakawa, on the east side of Hakata Bay, excavations revealed evidence of a moat and a circular semisubterranean house. Yusu and Itatsuke I jars, pots, bowls, and mounted dishes were excavated from the moat, along with planing knives, axes, polished stone stemmed arrowheads, whetstones, grinding stones, spindle whorls, polished stone daggers with handles, and beads made of jasper and amazonite of Korean origin. Metal artifacts included a reworked bronze arrowhead, a bronze chisel, and an iron arrowhead. Chipped stone arrowheads and axes of Jomon types were also found (Oda 1986:147-148).

Magarita, located on a small rise in the coastal basin of Karatsu Bay, has given evidence of about 30 semisubterranean houses with square floor plans. The pottery there is dominantly of the Yusu type, though burnished-red pots similar to those of Itatsuke I type were found as well. Associated with the settlement were also pottery jar coffins of Yayoi type and a small dolmen. Carbonized rice remains, triangular stone reaping knives, sickles, planing knives, axes, whetstones, polished stone arrowheads with and without tangs, polished stone daggers with handles, tubular jasper and jadeite beads, and clay spindle whorls of Mumun Korean origin were also found (T. Mori 1985:55-59; Oda 1986:150).

At Nabatake, on the western side of Karatsu Bay, archaeologists in 1980-1981 excavated 16 cultural layers that give perhaps the best available single picture of the Jomon/Yayoi transition. The lowermost levels, 16-13, dated to Early and Middle Jomon, as shown by characteristic pottery types. Through Final Jomon 
levels 12-9, chipped stone tools of Jomon types diminished, to be increasingly replaced by polished triangular reaping knives, planing knives, daggers, and polished stone arrowheads. The lower horizon of Level 8 was dominated by pottery of the Final Jomon Yusu-type, as well as pots, shallow bowls, mounted dishes, and some black-burnished as well as red-burnished vessels. There also appeared, however, more of the familiar Yayoi semilunar reaping knives, planing knives, and stemmed stone arrowheads, with the further addition of polished stone daggers with handles, tubular jasper beads, axes, and stone chisels. Finally, Level 8 added grooved stone adzes and more chisels of Korean origin, along with Itatsuke I pottery, marking the first Early Yayoi level (Karatsu City Education Committee 1993:29-30).

A large number of wooden tools also came to light at Nabatake, and these showed the same trends and revealed additional aspects of household life. Final Jomon levels produced wooden vessels, a red-lacquered wooden vessel cover, and short and long bows. The Early Yayoi level gave evidence of bows, harpoons, several wooden axe handles, a box, shallow vessels, dishes with handles, mounted dishes, a dipper, forks, a spoon, and other items. Foods no doubt served with some of these utensils are directly attested by some 250 carbonized rice grains of japonica type, while pollen analysis suggested that millet, barley, buckwheat, red bean, and sesame were cultivated along with rice at Nabatake (T. Mori 1985:60-70; Oda 1986:150-155).

\section{Summing up Cultural Linkages between Mumun Korea and Yayoi Japan}

As just reviewed, the earliest Yayoi farming settlements in northern Kyushu all share a set of characteristics that show them to constitute a cultural and historical unity. It is also clear that this pattern appeared as a functionally integrated system and that it arrived from Korea and replaced the previous Jomon huntingfishing-gathering way of life in northern Kyushu in a very short time. This is a conclusion that has come to be very widely shared among currently active researchers of the subject (Goto 1986:120-163; Harunari 1990:135-139; Hirose 1997:65-69; Kataoka 1999:47-53; Kyoto Cultural Museum 1989:9, 44; T. Mori 1985:74-75; Nishitani 1990:1-16, 1991:131-169; Oda 1986:141-192; Osaka Yayoi Culture Museum 1999:6-47; Shimojo 1989:24-26; Takakura 1995:283-288; Yan 1991:9-16).

Notably, the earliest Yayoi farming communities lay around the edges of Hakata and Karatsu Bays (see Fig. 5), still today Japan's most important harbor facing the Tsushima Strait and Korea Peninsula. The island of Tsushima lies $80 \mathrm{~km}$ from Busan on Korea's southeastern coast, and from Tsushima to Hakata Bay in Kyushu is a distance of less than $50 \mathrm{~km}$. A modern commuter hydrofoil covers the distance from Busan to Fukuoka City in a little over two hours.

As illustrated above, the new farming communities in Kyushu almost invariably contain pottery of two new types-Yusu and Itatsuke I. The Yusu type, named for a site near Fukuoka City, is ascribed to Final Jomon culture. The Itatsuke I type, named for a nearby site, is ascribed to Early Yayoi. The two types are effectively indistinguishable in their basic fabric, but Yusu jars are identified by an angular shoulder, slightly everted neck, narrow and flattened base, and incised appliqué bands encircling the shoulder and/or rim. Itatsuke I pottery, in contrast, 
is marked by deep jars with a straight vertical profile and slight eversion of the rim (see Fig. 2).

Detailed comparative analysis has recently established that much of the earliest Yayoi pottery of western Japan was either specifically of or directly derived from the Korean Mumun type that was widespread in southern Korea at the same time, particularly in manufacturing techniques (Osaka Yayoi Culture Museum 1999:34-37; Shim 1999:96-97) (see Fig. 3). Itatsuke I pottery, for example, is identified as stemming from either the Karak-ni type of Mumun Korea ( $\mathrm{J}-\mathrm{H}$. Kim 1972:93) or the Gongyeol-mun type (Harunari 1990:39) (see Fig. 2).

Likewise, the Yusu pottery, marked by dottaimon (appliqué bands encircling the shoulder and/or rim) and considered to have developed out of Japanese Jomon tradition, resembles the Doldaemun pottery of Korean Mumun tradition much more closely than it does pre-Yusu Jomon types, in materials, manufacturing, and firing techniques as well as in the way it was used (J-H. Ahn 2000:56-58; Shim 1999:47-56, 95-96). Some Yusu jars, with perforated rims, are considered to have been influenced by Gonyeol-mun ware, which had coexisted with it in Kyushu and southwestern Honshu (Kataoka 1999:31-44).

Songguk-ni pottery has been identified as occurring along with Yusu and Itatsuke I pottery in northern Kyushu, in nearby southwestern Honshu's Shimane Prefecture, and somewhat later in the Inland Sea region as far to the east as Okayama Prefecture. Its occurrence generally coincides with that of the Korean Gongyeol-mun type in northern Kyushu, and in southwestern Honshu it follows in time the Gongyeol-mun type (Kataoka 1999:77-78). Songguk-ni pottery directly influenced the red-burnished pots of Yayoi in terms of finger manipulation, clay, and firing (Shim 1999:87-93) (see Fig. 2).

New mortuary practices also appeared in northern Kyushu as an integral part of the early village-farming complex (Hirose 1997:65-69; Osaka Yayoi Culture Museum 1999:42-47, 86; Sahara and Kanaseki 1981:24). More than 700 dolmens are known from Kyushu, some 350 of them in Fukuoka and Saga Prefectures alone (Nishitani 1997:56-150) (Fig. 5). Considering that dolmens have been continuously destroyed in land-clearing efforts since ancient times, the original numbers were surely higher. The Kyushu dolmens, in their external form, were strikingly similar to kibanshik-type (go table-shape) dolmens common in southern Korea (Shim 1999:153-210) (Fig. 5). Soon after their arrival, however, dolmens of northern Kyushu underwent local modifications, particularly in the underground burial pit, with increasing use of jar coffins. Burial goods in the Japanese dolmens, while fewer in comparison to those found in Korea, were of similar kinds: jars and pots, including Songguk-ni type burnished red pots. In some cases, polished stone arrowheads and/or daggers, spindle whorls, and amazonite tubular beads were buried, as in Korea (Nishitani 1997:56-128).

Stone cist graves and jar burials appeared along with dolmens in northern Kyushu. The cist graves were small pits lined with thin vertically set stone slabs, identical to those known in southern Korea and like them containing polished stone daggers, red-burnished pots, and tubular jasper beads (T. Mori 1985:7374). Yayoi burial jars are clearly shown by their typology to be derived from Korean Mumun period burial jars, specifically those found in the Songguk-ni Culture of southern Korea (K-S. Kim 1994:186). Jar burials soon became numerically dominant in the Yayoi Culture and were the most persistent type of inter- 
ment throughout the Early, Middle, and Late Yayoi periods, from Kyushu north to the Kyoto-Osaka region and beyond.

Another burial form, similar to Korean graves and linked to higher status individuals, is the shukubo, a slightly raised mound encircled by a ditch. Called jukumyo in Korea, they began to appear during the Late Mumun throughout westcentral and southwestern Korea around 400 B.C. (W-K. Choi 2002:19-45). In western Japan, more than 4000 shukubo have come to light, from Kyushu to the Kyoto-Osaka region, some containing Songguk-ni and other types of Mumun Korean pottery (Osaka Yayoi Culture Museum 1999:82-88).

Early Yayoi residential structures comprised semisubterranean pit houses of both square and circular floor plan, very much as in southern Korea, and a significant number of Early Yayoi dwellings were of the Songguk-ni type with a circular floor plan and an oval pit in the center, which flourished in southern Korea between about 700 and 300 B.C. (Shintaku 1993:89-90) (see Fig. 4). As of 1987, more than 50 Songguk-ni-type dwellings were identified in Fukuoka Prefecture alone (Harunari 1990:121-122; J-C. Lee 2000:73-83; Miyamoto 1996:128; Nakano 1987; H-D. Shin 1993:337-361; Takesue 2001:102-103).

A number of the new Japanese farming settlements in the Yusu/Itatsuke cultural context also had moats, another characteristic feature of large Mumun period settlements in southern Korea. As in Korea, the purposes of the Japanese moats appear to have been varied, from military defenses to internal security and social demarcation (Terasawa 2001:26-28). Soon, the Songguk-ni settlement pattern spread southwest into the Saga region, resulting at Yoshinogari in the emergence of the largest moated agricultural community in Yayoi Japan (Saga Prefecture Kyoiku Iinkai 1990).

Another cultural feature connecting the Early Yayoi with Mumun Korea is the finding at Daepyeong-ni of skeletal remains of individuals who had undergone lower tooth extraction as adults, a custom that appeared in Early Yayoi society as part of the grieving process for dead family members (Jinju National Museum 2002 : 138).

Once established in northern Kyushu, the new cultural pattern, including Songguk-ni pottery and related artifacts, spread rapidly (see Fig. 6). Before the end of the Early Yayoi period it was established throughout the Inland Sea, the Kyoto-Osaka-Nara regions, and beyond, at least as far as the Nobi Plains around modern Nagoya (Osaka Yayoi Culture Museum 2005:16-21). By Middle Yayoi times it was flourishing throughout the Tokyo area and northern Honshu, albeit with significant modifications reflecting its encounter with a persistently strong Jomon tradition in those regions (Akazawa 1982:151-211). Surprising recent evidence shows rice-farming settlements in Aomori City, at the northern tip of Honshu, in Early Yayoi times. The presence of Ongagawa-type pottery at the Aomori site strongly suggests colonists traveling rapidly by water up the west coast of Japan, rather than expanding through the interior over generations (Japan Archaeological Association 1991:59-68).

\section{Appearance of New People in Japan}

The large and distinctive assemblage of some 175 Yayoi period human skeletons excavated during the 1950s from the cemetery of Doigahama in extreme south- 

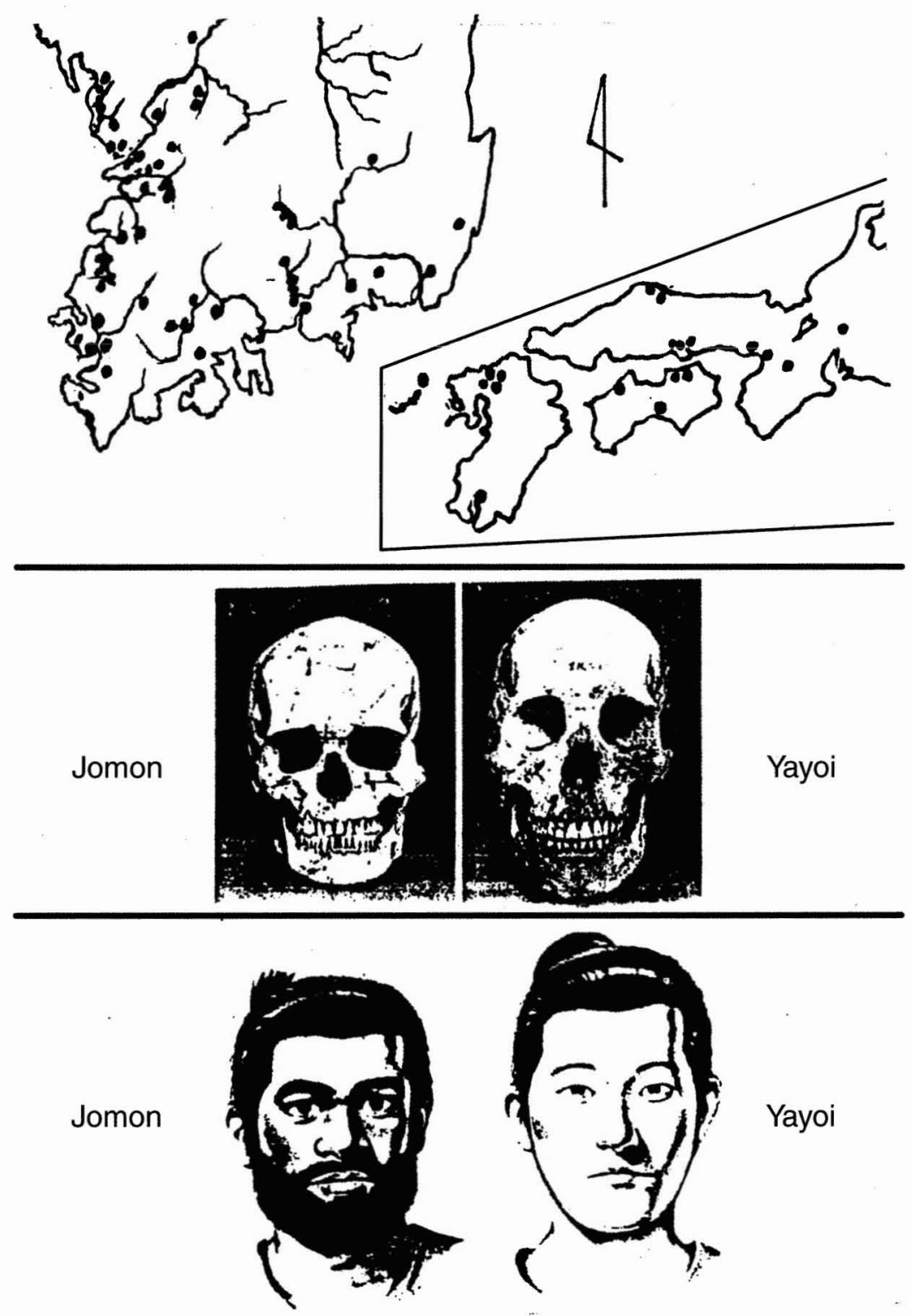

Fig. 6. Top: Distribution of Songguk-ni pottery and related artifacts (J-C. Lee 2000:59; Osaka Yayoi Cultural Museum 1999:36); middle and bottom: Jomon and Yayoi skeletons and their facial features reconstructed (after Baba 1997:26-27).

western Honshu, along with other accumulated evidence, led influential Japanese anthropologists to affirm the arrival of a new people, marked by tall stature and a long face, from Korea during the Yayoi period (Hanihara 1993:6-29) (Fig. 6). In subsequent years, a voluminous literature has developed on the physical anthropology of the Japanese, in which metric indices, blood group chemistry, nonmetric morphological traits, dental characteristics, and most recently, DNA studies on modern populations have been brought to bear on the question of Jap- 
anese origins. A strong consensus has emerged among Japanese and international scholars that the Yayoi immigrants came from Mumun period Korea and that they were mostly males who married indigenous Jomon women upon their arrival in Japan (Hanihara 1984:177-179; R. Tanaka 1997:102). Based on a thoroughgoing review of the literature, Hudson (1999:17) defines the Japanese as "the population that was formed in the Yayoi period through the immigration of peninsular farmers and their subsequent mixing with indigenous Jomon people."

The initial Mumun Korean migration into the Japanese archipelago, however, was only the beginning. According to a computer simulation of demographic and skeletal changes in prehistoric Japan, the archipelago's population increased from 75,000 during the Final Jomon to 5,400,000 during the Kofun period. The exponential increase in the course of 1000 years is attributed both to large-scale continued Korean migrations and to population growth in Japan fueled by the agricultural revolution (Hanihara 1993:14-23). More will be said below about significant post-Yayoi immigration from Korea during the Kofun period.

In the study of Yayoi agricultural origins, a number of Chinese and Japanese archaeologists have long maintained that "Chinese connections" linked prehistoric Kyushu directly to the Yangtze River basin of southeast China (An 1985:297-310; Higuchi 1986:121-126; Higuchi $1995: 282)$. Noting that jade earrings, tall wooden structures, certain plants, the custom of tooth extraction, and certain lithic tools and ethnographic features observed at some Jomon and Early Yayoi sites are similar to those found in the Yangtze River basin, these scholars posit that the technology of rice cultivation diffused directly from southeastern China to Kyushu across the East China Sea. Others (Wasano 1995:3-52), primarily on the basis of morphological analysis of rice grains found in China, Korea, and Kyushu, have also suggested a "direct East China-Kyushu" connection for the origin of Japan's rice cultivation.

The hypothesis of a direct Chinese connection will remain problematic, according to its critics, until it can adequately explain a number of crucial issues: (1) why the paddy field cultivation first appeared in the Hakata and Karatsu Bays-areas of northern Kyushu that are points in the archipelago closest to southern Korea - rather than along the southwest coastal region of Kyushu facing the East China Sea; (2) why only the short-grain O. S. japonica type, adapted to cool climate and grown in Mumun Korea, first appeared in northern Kyushu when both O. S. japonica and the long-grain O. S. indica types were grown in the Yangtze River basin; (3) why grooved adzes, triangular reaping knives, polished stone daggers, pottery vessels, settlement patterns, and mortuary practices closely associated with the early Yayoi farming communities are found only in southern Korea but not in the Yangtze River basin; and (4) why the initial paddy rice agriculture in Japan exemplified a whole complex identifiable with Mumun Korea's cultural system rather than that of the lower Yangtze River basin (Jeon 1986: 107-117; Takakura 1995:283-288; Tanaka 1997:102).

In a different vein, others have argued for an internal developmental process identifying Jomon society as the main actor in the development of Yayoi agriculture. The Korean immigrants, these scholars argue, appeared in Japan only after Jomon people had already established the Yayoi agrarian society through cultural interaction with the continent (Kanaseki and Osaka Yayoi Culture Museum 1995). A crucial weakness of this hypothesis, however, is its failure to identify 
sociocultural and economic pressures within Final Jomon society that would encourage the adoption of paddy rice agriculture, an extremely complicated and labor-consuming human endeavor. The native Japanese hunting-fishing-gathering Jomon economy had been self-sufficient for 10,000 years, and during the Final Jomon period population pressure in the Japanese archipelago, especially in the south, was less than it had been in earlier times. Hanihara $(1984: 140,1993: 16)$ has estimated that Jomon population throughout Japan had declined from 260,000 during the Middle Jomon to 75,000 during the Final Jomon, with only 10,000 people in Kyushu. A relatively small number of Jomon people living in an economically productive environment would have had no incentive to engage in agriculture, let alone paddy rice cultivation, the most arduous and labor-intensive form of food procurement activity of ancient times. In fact, for these reasons many Jomon societies in central and northern Japan resisted the adoption of paddy rice agriculture even as it was thriving in northern Kyushu (Akazawa 1982: 151-211).

Furthermore, archaeological evidence from Kyushu clearly shows that the earliest paddy rice agriculture appeared there suddenly and in the form of fully developed farming communities. There is no evidence for Jomon trial and error with paddy rice cultivation, but instead a picture of highly sophisticated agricultural technology arriving suddenly with Mumun farming people and their whole cultural system.

\section{What Motivated the Korean Influx into Japan?}

As previously noted, beans, peas, and sorghum were being cultivated in northwestern Korea by 1500 B.C., and by 1000 B.C. Koreans were growing paddy field rice throughout the peninsula. By about 600 B.C. the Gongyeol-mun and Songguk-ni Mumun societies had undergone an explosive growth in population and settlement size, and social stratification was well advanced (J-H. Ahn 2000:5456; M-Y. Song 2001 : 104-106). Much archaeological evidence shows that during the interval from 700 to 400 B.C., the fertile alluvial lands most suitable for agriculture between the Han River basin of central Korea and the southern coast were densely settled by large Mumun farming villages such as those at Misari, Daegok-ni, and Daepyeong-ni (J-T. Choi 1994:97-136; Jinju National Museum 2002; K-U. Lee 1994:136-153). By 500 в.C. Songguk-ni itself occupied more than 61 hectares, or $610,000 \mathrm{~m}^{2}$ of land that was partly enclosed by log barricades (K-S. Kim 1994:173-193). This was a size no Mumun village had reached before. The Mumun population at Geomdal-li was also exploding toward the end of the site occupation (Busan University 1995:253). Daepyeong-ni, on an alluvial river terrace about $20 \mathrm{~km}$ inland from Korea's southern coast, had more than 380 dwellings dated between about 600 and 400 B.C., and some $40,000 \mathrm{~m}^{2}$ of adjoining cultivated fields have been archaeologically identified. Neither site is wholly excavated, so these are conservative indications of their size. Daepyeong-ni was abandoned sometime in the 400 s B.C., for reasons currently unclear, and it is not known what happened to its people. In light of the evidence for many violent fires at Middle Mumun and later sites already mentioned, we can also posit that the incredible growth of population and settlement sizes during the Middle Mumun and succeeding periods resulted in social conflicts and warfare, which in turn would have put some of the Mumun population to flight. 
It was during this same interval of burgeoning settlements and violent destructions in southern Korea that village farming communities of Korean type began to appear in northern Kyushu, as has been detailed above. The conjunction is too well marked to be mistaken, and no complex theorizing is needed to understand why Koreans in these circumstances would have been drawn to the vast uncultivated plains of northern Kyushu. Certainly Kyushu was not an unknown land of mystery, as ample pottery and other evidence from both sides of the KoreaTsushima strait shows that people had been crossing back and forth since at least 6000 B.C., trading goods from each side (Jeong and Ha 1998:1-90; D-J. Lee 2000:35-96). Furthermore, Kyushu was very thinly populated by huntingfishing-gathering people, as compared to agricultural Mumun period Korea.

\section{TECHNOLOGICAL AND SOCIOPOLITICAL DEVELOPMENTS,}

$$
\text { C. } 400 \text { B.C.-A.D. } 400
$$

In this section, we present archaeological and historical syntheses on the development of technologies vital to expanding complex societies, as well as on the emergence of state-level societies in Korea and highly stratified elite classes in Japan. Korea's technological contributions to Japan's emerging elites are also discussed.

\section{Technological Developments in Korea: Bronze, Iron, and Dojil (Stoneware) Pottery}

While Yayoi society was developing in Japan, Mumun society in the Korea Peninsula was undergoing new technological and sociopolitical developments, largely under the influence of its northern Asian neighbors in the Liaoning region. Most prominent in this regard were the advancement of the local bronze industry and the introduction of iron tools, as well as the development of a Korean iron industry (Kweon 1997:112-115; K-M. Lee 1994:23-67).

The new bronze repertoire, known as "Korean slender dagger culture," was derived from the old Liaoning bronze tradition but developed a distinct character of its own, as local technicians perfected the art of bronze casting (K-M. Lee 1994: 135-156; Rhee and Choi 1992: 78). Unlike the bronzes of mainland China, with their overwhelming emphasis on ritual vessels, the Korean bronzes-now known from more than 100 sites-emphasized weapons and tools. These included bronze daggers, spears, halberds, arrow points, chariot fittings, and horse trappings, as well as artisans' tools such as chisels, adzes, needles, and fishhooks. Bronze ritual implements comprised mainly bells and multiknobbed mirrors. The most impressive array of bronze objects is found in elite graves, where bronze artifacts, especially the multiknobbed bronze mirrors, served as symbols of sociopolitical power and authority (C-K. Lee 1999:57-87). In an elite stone chamber burial at the Daejeon Goejeong-dong site, bronze mirrors were placed along with a bronze dagger and curved jewels as a set. This was the beginning of the threejewel sacred symbol tradition involving dagger, mirror, and curved jade, which continued for more than 2000 years through several historical periods.

In some cases, bronzes were also buried underground as part of communal rituals invoking blessings of safety, good health, and rich harvest ( $\mathrm{S}-\mathrm{K}$. Lee $2000: 23-56)$. The Korean bronzes flourished during the interval from 200 to 50 B.C., after which iron tools became increasingly more important. 
Emergence of Korean bronze technology also coincided with the appearance of new pottery forms, including black-burnished, long-necked jars, deep bowls with a clay stripe around the rim, and steamers with ox-horn shaped handles. By A.D. 1, these evolved into another form of earthenware comprising soft yeonjil and relatively hard gray-bluish kyeongjil potteries (or wajil pottery as applied to the southeastern repertoire). Unlike the Mumun pottery, these were wheel-thrown and marked by incised paddled surfaces with lattice or cord mark designs. While the yeonjil pottery was a continuation of the Late Mumun pottery, the gray-bluish kyeongjil ware was a new innovation influenced by Chinese Yuan kilns of the Warring States period, which had spread to the Liaoning region in 200-300 B.C. (S-J. Lee 1991:251-258). New mortuary practices also appeared involving the use of wooden coffins in earthen pits or in pits lined with slabs or small rocks.

Iron tools first appeared in the northern part of the peninsula between 400 and 300 B.C. (Kweon 1997:112-115; K-M. Lee 1997:89-91; K-H. Song 1997:96-100). The first iron implements, imported from the Yan State in southwestern Manchuria, comprised mainly weapons and agricultural tools. The former included spears and arrowheads, while the latter included wedge-shaped axes, spades, hoes, sickles, needles, fishhooks, and semilunar knives.

The practicality of the iron tools soon led Korean artisans to develop their own iron-working technology, as attested by the iron slag from Odong and iron molds from Daedong in the northwest; by 200 B.C., standardized iron artifacts were being produced in the north. Cast-iron tools of the north spread rapidly throughout the Korea Peninsula, as evidenced by the iron tools found at Songsan-ni and Seoksan-ni in the northwest, Ihwa-dong in the northeast, and Soso-ri, Hapsongni, and Namyang-ni in the south.

After about 150 B.C., local smithing appeared in southeastern Korea. Using wrought iron technology at first, as evidenced in a wrought iron workshop uncovered at Raeseong (in Busan), Korean smiths produced harder and more durable iron tools, including iron daggers, iron spearheads, iron chisels, iron hatchets, and pansang cheolbu (flat, rectangular iron-plate "axes"). At the same time or shortly thereafter, cast-iron technology began to be employed in iron tool production. The most prominent and also most abundant among the castiron implements were the joojo cheolbu (heavy wedge-shaped axes) (K-H. Song, 2002:39-60) (Fig. 7).

Availability of Han Chinese wrought iron technology after about 100 B.C. further facilitated local iron tool production. Consequently, the quantity as well as types of iron tools in Korea rapidly increased. Long swords, short knives with a round pommel, halberds, and arrow points of forged iron were added to the military inventory, while agricultural implements included iron spades, rakes, and sickles, the latter becoming most popular (K-H. Song, 2002:36-60).

Around A.D. 300, the elites of Shilla and Kaya commenced production of iron body armor and iron helmets. Initially they were in the form of vertical-plate cuirasses, which consisted of long and narrow iron plates fastened together vertically, first with leather strings and subsequently by riveting. Soon their number multiplied along with the growth of regional political powers, as evidenced in the archaeological remains of Yangdong-ni and Daeseong-dong tumuli in Kimhae and Bokcheon-dong in Busan. Around A.D. 450, the vertical-plate armor was replaced by lamellar armor made of $2.5 \mathrm{~cm} \times 5-9 \mathrm{~cm}$ iron plates, which provided much greater flexibility in heavily armed cavalry warfare. To the cuirasses were 

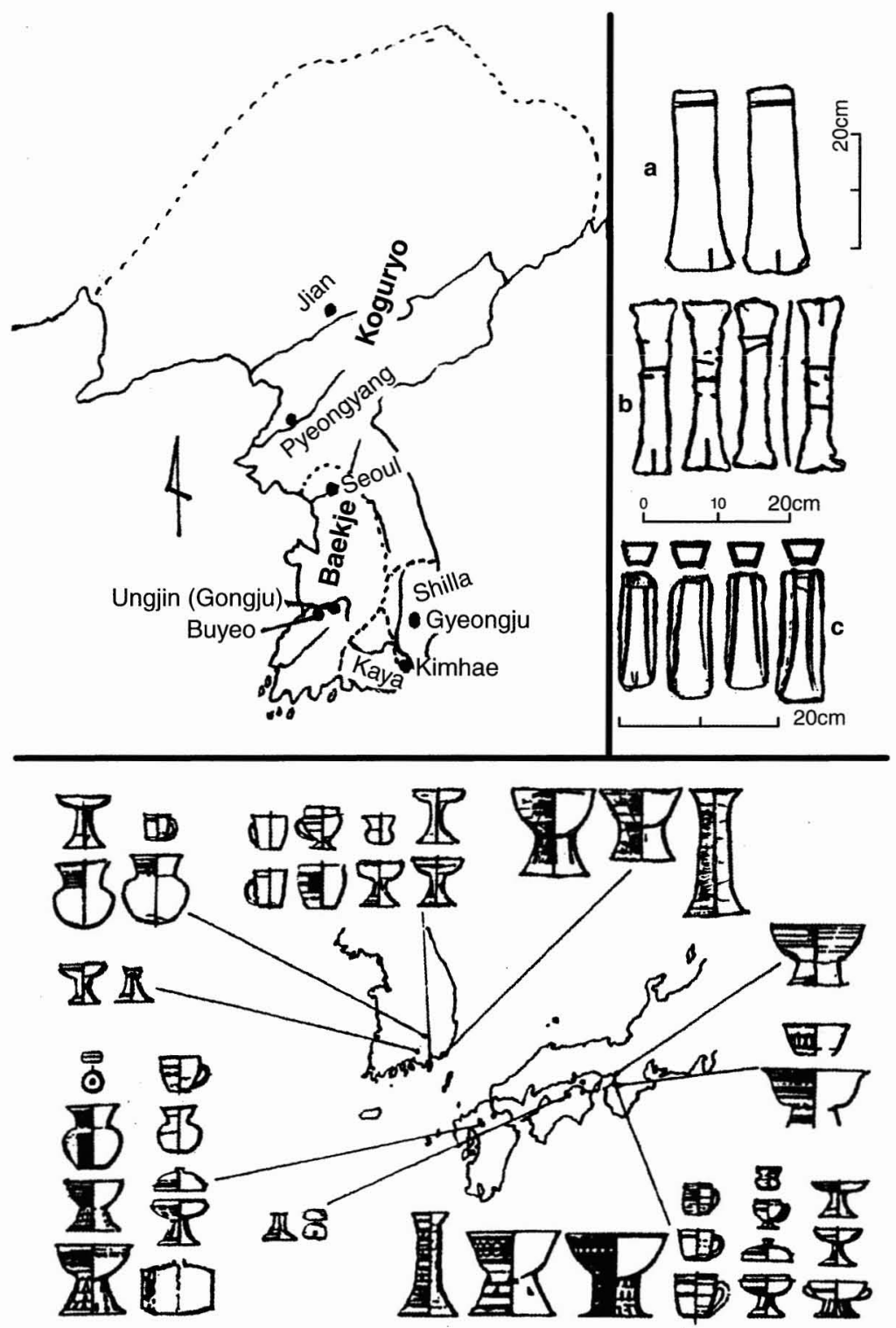

Fig. 7. Top left: Early states in the Korea Peninsula; top right: a: pansang cheolbu; b: cheoljeong; $c$ : joojo cheolbu; bottom: dojil (stoneware) pottery of southeastern Korea and sue pottery produced in Japan (after Sakai 2004:342).

added neck and shoulder guards. There also appeared body armor and head guards for horses (Barnes 2000:60-95; Bokcheon Museum 1999:67; Kim and Song 2003:276-302; Shin 2000:261-276; J-S. Song 2003:3-7, 54-75).

Between A.D. 300 and 400, the pansang cheolbu became thick, flat iron ingots called cheoljeong (tettei in Japanese) (see Fig. 7). Like the pansang cheolbu, the cheoljeong were used as money in addition to being exchanged as raw iron plates. As precious goods, they were also buried in elite graves, sometimes in lavish quan- 
tity. For example, 1332 sheets of cheoljeong were found in the Hwangnam Great South Tumulus in Gyeongju (Gyeongju National Museum 1996:75-82).

Two well-preserved ancient iron industrial complexes have come to light at Seokjang-ni in Jincheon and at Hwangseong-dong near Gyeongju in southern Korea, dated to the 100 s and 300s A.D., respectively. The former was a large iron production center, while the latter was a large iron tool manufacturing industry (Y-H. Lee 1997: 101-105; Yeongnam Archaeology Association, 1991).

According to chemical analyses of the iron tools, technicians of Baekje and Kaya succeeded in producing steel with heating and water-quenching methods and an advanced bellows system capable of producing high heat reaching $1250-$ $1270^{\circ} \mathrm{C}$. In manufacturing weapons and tools of high quality, casting was largely replaced by the forging method (Pohang Combined Steel Industries Technological Research Institute and Korea University 1985:50-52, 1986:40-43; T-C. Roh 1998:49-63).

Along with advanced iron and steel technology, there also appeared new pottery technology producing stone-hard dojil ware around A.D. 250, coinciding with the emergence of early states in Korea (Barnes 1992:197-208; S-J. Lee 1998:45-79). As an advanced form of the previous hard gray-bluish kyeongjil pottery, the dojil stoneware technology involved clay suited for high firing, sloping tunnel-type kilns designed to achieve reduction or deoxidation at high heat of $1100-1200^{\circ} \mathrm{C}$, or even higher, and ceramic specialists adept at the potter's wheel (S-J. Lee 1991:251-258; National Museum of Korea 1997:2-112). Dojil pottery of Baekje was marked by incised and paddled surfaces with lattice or cord mark designs, while that of Shilla and Kaya was noted for several kinds of geometric linear designs, including triangles, waves, circles, squares, and spirals, among others. In terms of vessel types, Baekje was noted for jars with short, straight necks and tripod dishes, while the Shilla and Kaya repertoires included numerous mounted dishes, pottery stands, and long-necked jars (Fig. 7).

Closely related to the emerging early states and their political articulations, the stoneware pottery was under state control in both manufacture and distribution within various regions of the peninsula; consequently, each region manifested variations in vessel types and surface designs, even as they shared common features in the overall vessel repertoire. Functionally, the dojil vessels were produced as part of ancient Korea's mortuary system and were used as ritual vessels for the dead, particularly among the elites of the newly emerging states. (S-J. Lee 1998:45-79; National Museum of Korea 1997:2-112).

\section{Sociopolitical Developments in Korea}

In the realm of political developments, a state-level society had emerged in northwestern Korea by about 300 B.C. known as Joseon (Chaoxian in Chinese; Chosen in Japanese), according to ancient Chinese records that include the Shiji, compiled by Sima Qian (145-85? B.C.); the Hanshu, compiled by Bangu before A.D. 100; and the Weillue, compiled c. A.D. 250 (Nelson 1993:202-205). Around 190 B.C., Wiman, a military leader from the Chinese frontier state of Yan, took control of Joseon and established his capital in Wangkom-seong, present-day Pyeongyang. According to the Shiji, hereditary kings ruled Wiman Joseon with the support of an elite bureaucracy and a powerful military. They exercised political hegemony over other polities, as well as practicing their own political 
autonomy. They also controlled trade networks. Displaying these characteristics, Wiman Joseon was clearly a full-fledged state (M-L. Choi 1992:185-189), and the existence of such an independent political and military power on its northeastern periphery was not acceptable to the newly emerging empire of Han China.

Thus, in 108 в.C. the Chinese emperor Wu Di sent 50,000 army and 7000 naval forces against the Wiman Joseon capital at Pyeongyang, which fell after more than a year of fighting. Wu Di promptly built the Lolang commandery there as a frontier outpost of the Han Empire, and, toward the end of the Later Han dynasty (A.D. 25-220), the commandery of Taifang was also established farther south. Chinese imperial administration of the region persisted for some 420 years, until Lolang and Taifang were toppled militarily in A.D. 313-314 by the state of Koguryo (K-B. Lee 1996:33-43).

Throughout their existence, Lolang and Taifang were multicultural polities comprised of Chinese residents and native Koreans. Their taesu (governors) were Chinese officials appointed by the emperor, but the taesu chose their own local administrative officials from among local elites (Takaku 1995:277). The commanderies not only secured China's frontier with the "northern barbarians" but also functioned as Chinese embassies to various small polities in the Korea Peninsula, Japanese archipelago, and elsewhere, receiving tributes and granting honorary ranks and gifts to local leaders. The commanderies were also important trading entrepots for Chinese bronze mirrors, lacquerware, long iron swords, and bronze vessels, in addition to being points of dissemination of advanced Chinese technical, political, and intellectual culture to various centers throughout southern Korea and to some extent to northern Kyushu (K-B. Lee 1996:42-43).

As Han China held its commercial, military, and political foothold in northwest Korea through Lolang and later Taifang, the sociocultural fabric of ancient Korea, then known as Joseon, began to undergo disruption bit by bit as Chinese cultural elements, highly valued by local residents, found their way into the native Korean sociocultural milieu. This process brought changes, first among Korean residents in Lolang and Taifang and later among local polities, changing earlier political and tributary relationships (Eckert et al. 1990:14). Those local polities that by reason of geography had closer contacts with the Chinese commanderies reached political and military maturity much sooner than others. This was especially the case with Koguryo and Baekje, two Korean polities sharing physical borders with Lolang and Taifang in the north and south, respectively (see Fig. 7).

By about A.D. 200, Koguryo, a confederation of horse-riding seminomadic tribes located in the middle reaches of the Yalu River, had emerged as a powerful force, and by A.D. 300 it had become a centralized state with its capital at the walled city of Jian (Gang 2002:1-23). Having become strong enough to challenge Imperial China, it expelled the Chinese garrisons at Lolang and Taifang in A.D. 313-314. To undergird its national unity, in A.D. 371 Koguryo adopted Buddhism and established a National Confucian Academy, and in the following year it promulgated a code of administrative law. "Buddhism would give the nation spiritual unity, the National Confucian Academy was essential to instituting a new bureaucratic structure, and the administrative code would systematize the state structure itself" (Eckert et al. 1990:26).

During the reign of King Kwanggaeto (A.D. 391-413), Koguryo reached a 
zenith of political and military power, expanding its political and military influence to the tip of the Korea Peninsula in the south and to the heartland of Manchuria in the north. Thousands of impressive piled stone and other mounded tombs of Koguryo aristocracy, still standing in Jian and Pyeongyang, which became the Koguryo capital in A.D. 427, bespeak the glory and grandeur of Koguryo.

Baekje, located on the lower reaches of the Han River in and around modern Seoul, also came into cultural contact with the Chinese commandery of Lolang in the 100s and 200s A.D., as known from archaeological items found in the Poongnap Earthen Fortress, Baekje's early capital (K-T. Lee 1996:14-15; Seoul Museum of History 2002:140-143). Establishment of the Taifang commandery in A.D. 204, just north of Baekje territory, further spurred the growth and advancement of Baekje. By about A.D. 250 Baekje had emerged as a full-fledged state, undergirded by an elite bureaucracy of six administrative departments and 16 offlcial ranks, with colored official vestments for different ranks. Militarily, Baekje was also formidable enough to lead allied chieftains in military attacks against Taifang, killing its repressive administrator about A.D. 246 (K-T. Lee 1996:16).

During the reign of King Keunchogo (A.D. 346-375), Baekje embarked upon territorial expansion, as well as solidifying its centralized monarchy based on hereditary kingship and Confucian learning. Subsequently, in A.D. 384, Baekje adopted Buddhism as the spiritual foundation for national unity (K-B. Lee 1996:62). The massive earthen fortress of Poongnap Toseong-constructed in the second and third centuries A.D., $3.5 \mathrm{~km}$ in circumference, encircling an oblong-shaped city of $600,000 \mathrm{~m}^{2}$ - bespeaks Baekje's power in the period A.D. 200-400 (Seoul Museum of History 2002:22-28). Claiming a genealogical relationship with the royal founders of Koguryo, early Baekje kings constructed massive Koguryo-style piled stone tombs in the Seoul area. One tomb, now restored, is considered the largest of the kind ever built in northeast Asia. Sometime during the 300s, the early piled stone tombs were replaced by corridor tombs designed for multiple family burials, which soon became the standard mortuary form for Baekje elites (N-S. Lee 1992:75-113). In Baekje, beginning in the 500s, the corridor tomb style of construction was used by the central government as an instrument of political communication, and local elites were expected to adopt them as soon as they came under Baekje hegemony as a formal expression of allegiance to the Baekje court. Thus corridor tombs serve as a major archaeological marker for Baekje's political domination of a broad area (N-S. Lee 1995:460-468).

Elsewhere on the peninsula, about 70 small polities, or guo, as reported in the Chinese Weizhi of about A.D. 300 were growing, competing, and sometimes confederating as needs arose. About 50 such polities on the west, between Baekje and the southwest coast, were known collectively as Mahan. About 10 polities along the lower Nakdong River basin were known as Byunhan, and about 10 polities in Korea's southeast corner around Gyeongju were known as Jinhan. Having first appeared during Korea's Early Iron Age (400-100 B.C.), these polities were essentially advanced chiefdoms. In time, step-by-step, those in the west were incorporated into Baekje, while those in the south were drawn into Shilla, which was emerging as the paramount state in the Gyeongju area.

By about A.D. 300, Shilla had emerged as a rich and formidable power. It had a distinctive culture, marked by highly advanced gold and silver smithing technology and unique mortuary practices that involved huge stone piled circular tumuli 
with internal wooden burial chambers containing rich burial goods (B-Y. Choi 1998:1-34). The circular Hwangnam Great South Tumulus, constructed between about A.D. 300 and 400 and the largest burial tumulus ever built in the Korea Peninsula, has yielded more than 3000 prestige items. These included some 1500 stoneware (dojil) pottery vessels, 1330 sheets of raw iron (cheoljeong), and more than 300 iron weapons, in addition to iron body armor, iron farm tools, and iron horse gear and horse trappings. Symbolic and decorative items included gilt bronze crowns, gold crown fittings, gold necklaces, a gold and silver belt, gold earrings, gold bowls, silver spoons, gilt bronze horse ornaments, long iron swords decorated with gold and silver ornaments, and a pair of silver knee protectors, among other items (Gyeongju National Museum 1996:75-82).

As for those polities along the lower reaches of the Nakdong River, they developed into a dozen small, fiercely independent states known collectively as Kaya. For about 200 years, from A.D. 200 to A.D. 400, Gumkwan Kaya in and around modern Kimhae was supreme among all Kaya states in commerce and economy.

Limited in land suitable for agriculture, the Kaya states embarked on iron industries as the foundation for their economic power and political strength. The attraction of iron made the southeast coast of Korea an international melting pot, where traders from all parts of northeast Asia, all the way from Lolang and Taifang to Wa in northern Kyushu, met and exchanged goods. The elite tombs of Daeseong-dong and Bokcheon-dong in Kimhae and Busan, respectively, dated between A.D. 300 and 400, have revealed an abundance of prestige goods, including iron weapons, iron body armor, iron helmets, iron tools, stoneware pottery vessels, precious stone jewelries, horse gear, bronze mirrors, and bronze cauldrons, among other items (Bokcheon Museum 1996; K-C. Shin and J-W. Kim 2000). (For extensive discussions on the origins of Korea's early states, see Barnes 1990:113-153.)

Thus, by about A.D. 400, the Korea Peninsula had become a land of explosive growth and dynamic advancement in technology as well as in the sociopolitical arena. In the north, Koguryo was active as a powerful military state ambitious for territorial expansion, and in the center Baekje was growing as a formidable state. It had advanced iron technology, a formalized governmental structure, Buddhism, and a large urban population, and it was gradually absorbing numerous chiefdoms scattered in southwestern Korea. In the south, Shilla and Kaya had emerged into states of varying sizes out of numerous earlier and smaller chiefdoms, competing for land, resources, and trade advantages. They were also making great advancements in the production of iron weapons, iron body armor, iron tools, stoneware pottery, as well as in gold and silver smithing, construction of huge tombs, and agricultural expansion through land reclamation and construction of dams and dikes.

\section{Sociopolitical and Technological Developments in Yayoi Period Japan}

In the meantime, the establishment of paddy field rice agriculture had brought about fundamental changes within Yayoi society-organizationally, economically, and politically (Hirose 1997:111-134; Komoto 1997:104-110). By around 200 B.C., regional power centers were emerging in northern Kyushu among 
growing farming villages. Takesue $(2002: 25-58)$ has sketched the growth of social stratification in northern Kyushu during Middle Yayoi times through a comparative analysis of bronze-containing burials there. During the first half of the Middle Yayoi, in the Sawara Plains around Fukuoka, all bronze-bearing sites except one had only one or two bronze artifacts. The Yoshitake site, however, had 24. Takesue accordingly posits a three-tier stratification for the area: a base tier of scattered villages with no elite residents owning bronze artifacts; a second tier of villages with several elite residents owning one or two bronze artifacts; and the top tier, comprised by Yoshitake, which had multiple elite burials and many bronze artifacts.

During the second half of the Middle Yayoi, after A.D. 1, this changed. A three-part stratification remained, but two regional centers emerged: Sugu Okamoto in the Sawara Plains and Mikumi Minamishoji in the Ito region farther west. The two revealed approximately equal numbers of high-status artifacts, but their totals were far above those of all other subregional centers. A jar coffin at Sugu Okamoto contained 4 bronze daggers, 5 spearheads, 1 halberd, 35 Chinese mirrors, 1 magatama bead, and 12 tubular beads. At Mikumi Minamishoji, two jar coffins within an elite grave held 1 bronze dagger, 2 spearheads, 1 halberd, 35 Chinese mirrors, 2 jade magatama beads, more than 60 tubular beads, 8 gilt-bronze ornaments, and 5 jade pendants. At this period, most other chiefly graves in northern Kyushu contained only a few bronze artifacts. Yoshitake, previously in the top position in the Sawara Plains, was now a member of the second tier under Sugu Okamoto, and Mikumi Minamishoji became dominant over other chiefly centers in the Ito region farther west. In both areas the lowest stratum consisted of villages with no elite members, as before (Kyushu Historical Resources Center 1980: 1-48; Takesue 2002:25-58).

In the Weizhi, it was reported that there were $30 \mathrm{guo}$ or local polities of people called Wa in western Japan during A.D. 250-300 and that in the earlier days there had been about 100 guo. This account suggests that during the Late Yayoi period, around A.D. 100 and shortly thereafter, a process of political consolidation was ongoing in which many hitherto independent polities were being brought into about 30 confederated guo, each of which controlled a fairly large territory (Terasawa 2004:26-43). Beginning in the middle first century A.D., some of the emerging local chiefs in the Karatsu and Hakata Bays engaged in trading with Korea's southern coast as well as with Chinese outposts at Lolang and later at Taifang. From Korea they imported iron ingots, weaponry, and agricultural tools, and from the Chinese trading posts they obtained prestige goods-particularly bronze mirrors.

The bronze implements, an integral part of the growing Yayoi elite culture and its sociopolitical communication, initially all came from the Korea Peninsula. Korean bronze artifacts found in northern Kyushu during Early to Middle Yayoi typically do not occur in large numbers at individual sites but are widely distributed. At Arita was found one long spearhead; at Imori Takaki, one multiknobbed bronze mirror; at Iikura Karaki, two slender bronze daggers; at Higashi Irube, two slender bronze daggers; at Ukikunden, one multiknobbed bronze mirror and one slender bronze dagger; and at Nokata, two slender bronze daggers. Clearly a special place was Yoshitake, which yielded 1 multiknobbed bronze mirror, 3 short spearheads with a base ring, 4 long spearheads, and 16 slender bronze daggers. By 
the beginning of Middle Yayoi, around 200 B.C., bronze artifacts had spread thinly throughout western Japan as far as Okayama on the Inland Sea.

As was the case in Late Bronze Age Korea, the bronze mirror and bronze dagger became symbols of power, and soon curved jade (magatama) was added. In time, ancient Korea's "three treasures"-bronze daggers, bronze mirrors, and curved jade-became the sacred symbols of Japan's imperial power (Yanagita 1992: $27-40)$.

Local production of bronze artifacts got well under way in Japan during Middle Yayoi times (Iwanaga 1991:114-119; Takesue 1985:129-147). Stone molds found primarily in the context of Korean-type pottery at Habu, Yoshinogari, Motomura Minami, Hirabaru, Matsumoto, and other Yayoi sites in north Kyushu's Saga Plain suggest that the bronzes were at first made by immigrant Korean artisans. The local items are so strikingly similar to Korean originals that even experts have difficulty distinguishing them (Goto 1987:8-17; Kataoka 1999: 149-202; Yanagida 1987:17-26).

Soon, Japanese productions began to take on their own distinctive character. In Kyushu, Japanese-made slender bronze daggers, halberds, and spearheads underwent a process of size exaggeration, even doubling in length and width, apparently for use in ritual and political communication. In the Kyoto-Osaka-Nara region, bronze bells based on small Korean prototypes also grew greatly in size, becoming an order of magnitude larger than their small Korean predecessors. Also in Late Yayoi times, Yayoi chieftains began importing Han Chinese bronze mirrors from Lolang and Taifang and soon began producing copies locally.

Iron and its technology appeared in northern Kyushu about 200 B.c., almost simultaneously with bronze, and for almost 700 years thereafter the Japanese archipelago depended on iron from Korean sources for agricultural implements and weaponry (Azuma 1999:417-438; Murakami 1998:83-92). Yayoi people initially used wedge-shaped iron axes, hatchets, and chisels brought from Korea, but local smithing of imported Korean ingots appeared in northern Kyushu soon after 200 B.C. and had spread as far as the Kyoto-Osaka-Nara region by the end of the Middle Yayoi, about 100 A.D. Local smiths made sickles, adzes, hatchets, chisels, fishhooks, knives, arrowheads, and other items, but long swords with round pommels, spearheads, and stemmed and willow-leaf arrow points were still imported from Korea until 250-300 A.D. (Takesue 2002; Terasawa 2004:26-43).

The biggest archaeological news of recent years in Kyushu has been the discovery and large-scale excavation of Yoshinogari, a Middle and Late Yayoi site in Saga Prefecture some $30 \mathrm{~km}$ southwest of Fukuoka City. Yoshinogari is a moated and palisaded community that spreads over many hectares and is said to be the largest Yayoi site yet confirmed in Japan. It contains an internal precinct, also moated and palisaded, that shelters a rich elite cemetery and large public buildings, and elsewhere the site gives evidence of Songguk-ni-type residences, protected storehouses, bronze artifacts, bronze-working technology, dolmen burials, and pottery of specifically Mumun type, among much other evidence of Korean antecedents. Yoshinogari is unquestionably a community of the Songguk-ni type, which was widely established throughout southern Korea in later Mumun/Bronze Age times.

From its abundance of archaeological data, Nishitani (1989:127-132) has become convinced that "ancient Korea and its technology were greatly involved in 
the birth of Yoshinogari as well as in the process of state formation in the Saga Plains." There is widespread consensus among Japanese archaeologists that Yoshinogari must have been the center of one of the Japanese guo identified in the Weizhi, and many contend-though there are also influential dissenters-that it probably was the capital of Himiko, famed queen of the country of Yamatai, in the Land of Wa, as the ancient Chinese called Japan.

Cultural and sociopolitical developments analogous to those in Kyushu appeared elsewhere in western Japan during Late Yayoi. Farming villages had spread as far north as the Tokyo region and beyond. Around A.D. 200, in Izumo on the Japan Sea coast of Shimane Prefecture, in Okayama on the Inland Sea, and in the Kyoto-Osaka-Nara region at the head of the Inland Sea, very large Yayoi communities such as Karako are known, and impressive mound tombs such as Tatetsuki and Uriu were being constructed (Kondo 2005:189-216; Sakurai City Buried Cultural Property Center 2005:2-13; Terasawa 2004:39).

Around A.D. 250, in the Nara basin at Makimuku, near the base of Mt. Miwa, a thriving Late Yayoi settlement began to construct zempo koen (or keyholeshaped) mounded tombs, such as Hokenoyama Kofun, for its ruling elites. The Hashihaka Kofun of the same period was a $280 \mathrm{~m}$ long zempo koen tumulus, and during the 300s a number of other large zempo koen tombs were constructed in the area, including the Mezri and Kurozuka kofuns. Thus by A.D. 250-400, the Makimuku elites could command a labor force strong enough to engage in monumental construction.

RISE OF MILITARY AND POLITICAL ELITES IN KOFUN PERIOD JAPAN,

$$
\text { A.D. } 400-500
$$

In this section we focus on the transition from the Late Yayoi/Early Kofun periods to the Middle Kofun period, marked by revolutionary sociocultural transformation in Japan and the influx of Korean immigrants. Special attention is given to contributions made by Korean immigrants to the growing Kofun society in light of archaeology.

\section{Early Kofun Period}

The construction of monumental tombs opened a new era in ancient Japan called the Kofun period (c. A.D. 250-650). Culturally and technologically, however, the Early Kofun period (c. A.D. 250-400) was largely an extension of the Late Yayoi pattern. As with Yayoi, Early Kofun was primarily agrarian, religious/magical, and ritualistic in its sociocultural articulations, especially at the elite level. "We characterize the Early Kofun period (fourth century) by its grave goods," states Wada (1986:350-351), "some of a magical nature such as bronze mirrors, beads, swords, and jasper bracelets deposited in wooden coffins manufactured from split and hollowed-out logs.... Research reveals many Early Kofun cultural elements to be a continuation of Yayoi social characteristics." This observation has been emphasized by others. Egami (1967:158-161) states, "There is a fundamental difference between the culture of the Early Kofun period and that of the Middle and the Late Kofun in terms of their basic character. There was an intimate relationship between the Early Kofun and the Yayoi Cultures, so that Umehara Sueji 
wished to include the Early Kofun in the Yayoi cultural period." In contrast, the elite culture of the Middle Kofun period emphasized iron weapons and horse gear, with a focus on military themes (Naoki 1992:140). Another striking point is that the Early Kofun tombs were constructed mainly in the Nara basin and mostly on the top of ridges or on foothills, while those of the Middle Kofun period were built in the Kawachi plains near present-day Osaka (Barnes 1988:249156; Naoki 1992:140). Politically, the archipelago of the Early Kofun period was still a land of numerous regional powers or chiefdoms without any central government.

During the Early Kofun period, Kofun society also lacked many of the cultural and technological elements that came to characterize Japan's subsequent unified Yamato state. It lacked a literate bureaucracy, efficient transportation, and critical technologies for iron production and steel making. It lacked skills for monumental construction such as stone masonry, the making of tiles, and the dam and dike construction essential to land reclamation. It lacked mounted cavalry and advanced military gear such as the iron body armor so effective in mounted warfare. It lacked a formal governmental structure with functional departments. It lacked a unified spiritual ideology undergirding the national unity. And it lacked much in the way of awe-inspiring prestige goods for the elite leaders and officials, such as gold and silver paraphernalia.

\section{Korean Immigrants and the Middle Kofun Period}

All this changed during the Middle Kofun period, as tumultuous events were unfolding in the Korea Peninsula, spurring waves of Koreans to sail across the sea and reach the Japanese shore in search of new lands. According to archaeological criteria developed by Kameda Shuichi for toraijin settlements (specifically Korean settlements in Kofun period Japan), the Korean immigrants, upon reaching the Japanese shores, fanned out. They settled in various parts of the archipelago, all the way from Fukuoka in northern Kyushu to Okayama on the Inland Sea, to the Kyoto-Osaka-Nara area, to Gumma north of Tokyo, and to Sendai in northeastern Honshu (Kameda 2003a:1-14, 2003b:55-65, 2005:1-16; Fig. 8).

By far the largest Korean settlements were concentrated in the Kinai region, in the Nara basin, and the Kawachi plains of the present-day Kyoto-Osaka-Nara area, which became the center of political power in the Kofun period (see Fig. 8). Archaeological finds from many sites that document this Korean influx include distinct Korean yeonjil pottery types, unique Korean vessels such as portable cooking ovens (kamado), residential buildings with ondol (the traditional Korean underfloor heating system) and thick walls, iron-forging tools and an advanced bellows system, horse-raising farms, abacus-shaped spindle whorls, and burials containing such items, among other features (see Fig. 9). These Korean cultural features, according to Kameda, moved to the Japanese archipelago not so much as isolated artifacts or trade goods but as integrated cultural systems of the Korean immigrants (Kameda 2003a: 1-14, 2003b:55-65, 2005:1-16).

The sociopolitical turbulence in the peninsula followed Koguryo's decimation, in A.D. 313-314, of the Chinese commanderies of Lolang and Taifang and its subsequent southward move to occupy Korea's northwest. Threatened by Koguryo's move, Baekje countered, bringing the two formidable powers into fierce 

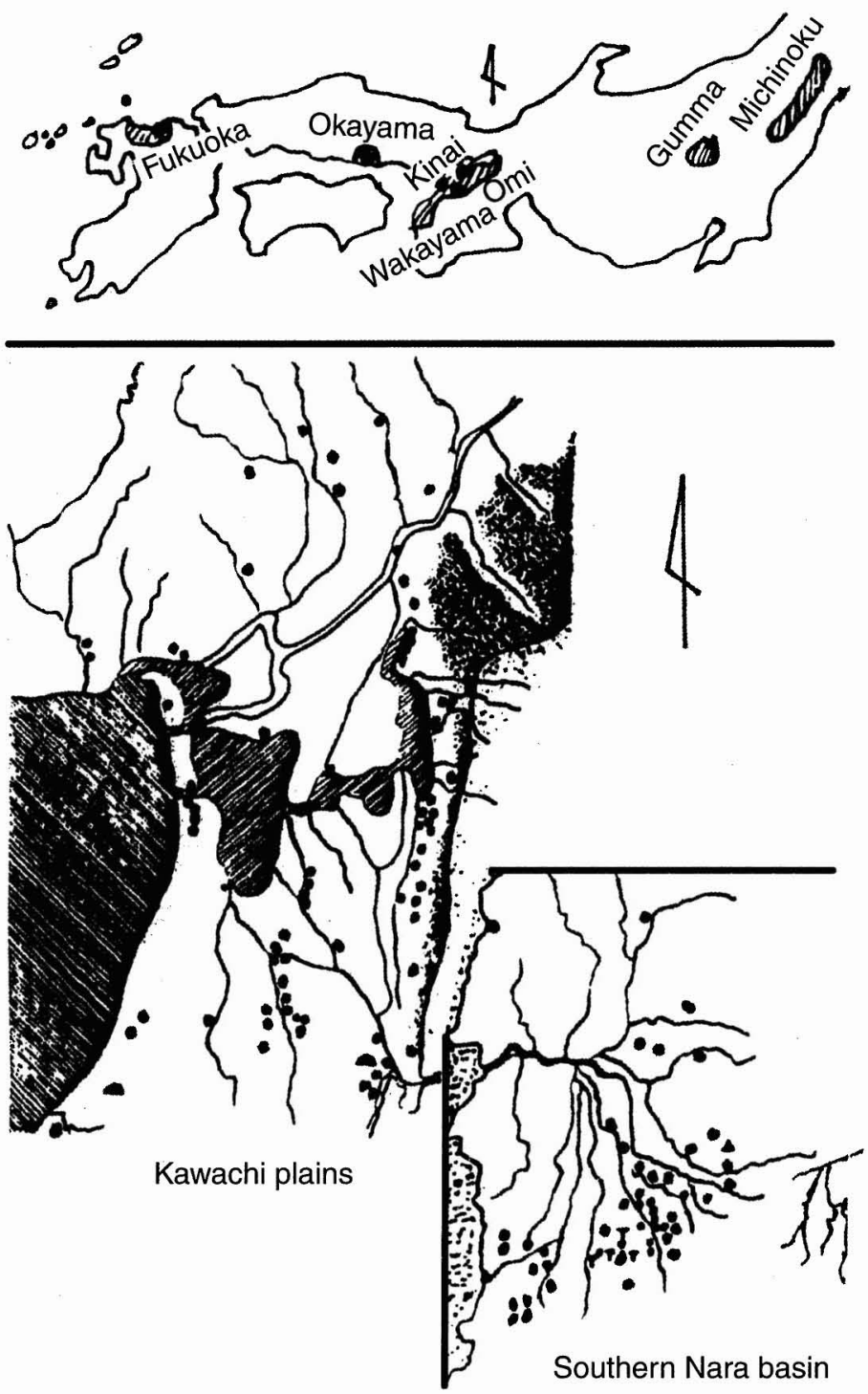

Fig. 8. Top: Korean settlement concentrations in the Japanese archipelago, A.D. 400-600; bottom: Korean settlements in Kinai (after Kashihara Archaeological Research Institute Museum 1999:73; Osaka Chikatsuasuka Museum 2004:91).

military conflicts. In A.D. 371, King Keunchogo of Baekje marched to Pyeongyang, now under Koguryo control, with 30,000 troops, killing Koguryo king Goguk Weon. This marked the beginning of 300 years of unceasing warfare and regional conflicts in the Korea Peninsula, lasting until about A.D. 670.

Of the many peoples involved, those of Baekje and Kaya suffered the most, as they became the primary targets of Koguryo invasions. In A.D. 400 Koguryo forces, 50,000 strong and supported by a heavy armored cavalry, dealt a devastating blow to Gumkwan Kaya, the richest and most advanced Kaya state in south- 


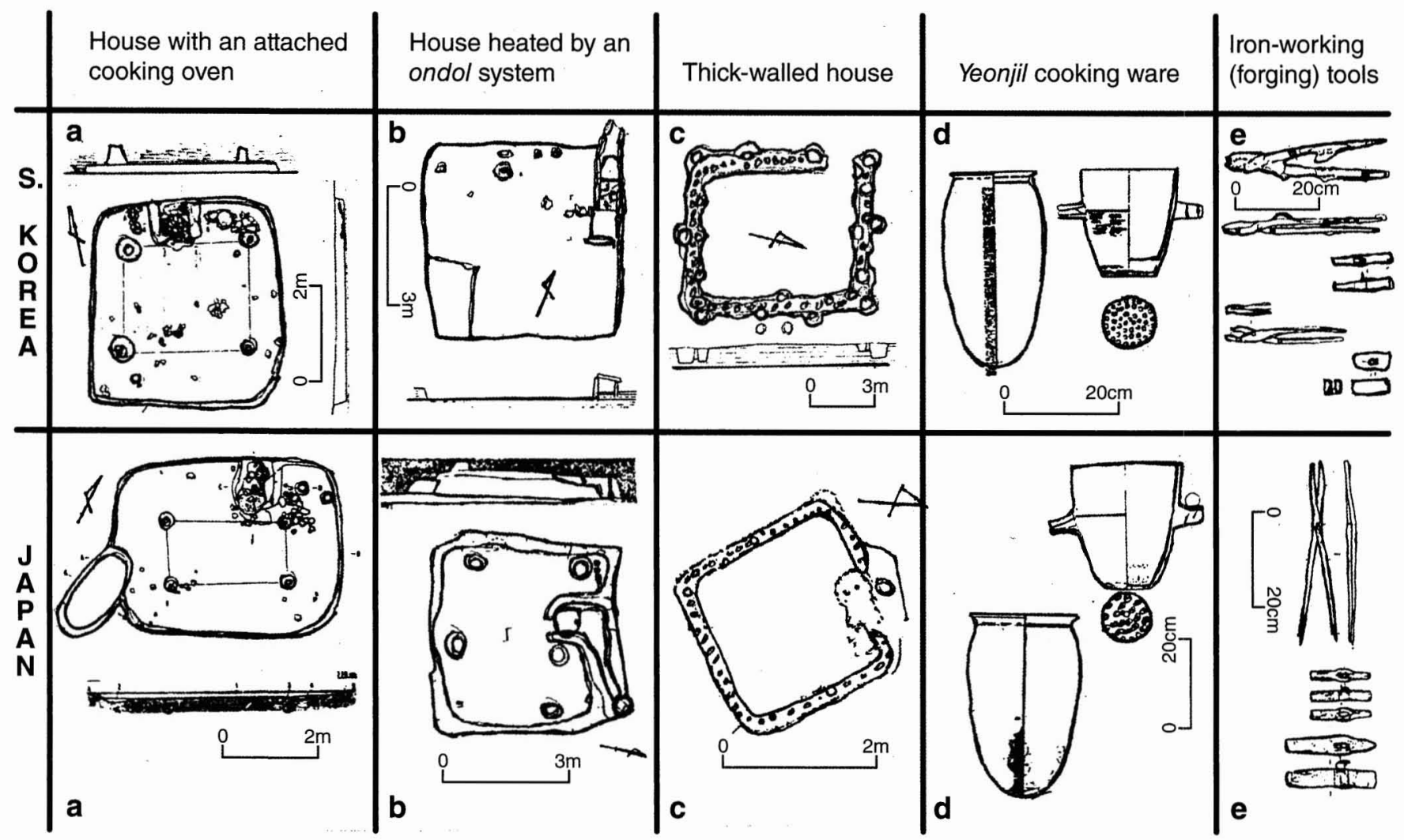

Fig. 9. Archaeological markers for Korean immigrant settlement sites in Japan, c. A.D. 400-600: top: Archaeological features of southern Korea (a: Mokp'o National Univ. Museum 2003:247; b: Y-C. Lee 2002: 48; c: J-Y. So 2004:68; d: S-R. Choi 1993:161; e: K-H. Song 1995: 152); bottom: the same features found in Japan, A.D. 400-600 (a: Kameda 2004a:79; b: Kameda 2003a:3; c: Gongju National Museum 1999:60; d: Kameda 2003a:3; e: Kameda 2004a :82). 
ern Korea, for assisting Baekje and Wa Japan against Shilla, Koguryo's ally. In A.D. 475, after several more fierce battles, Koguryo finally sacked the Baekje capital in Seoul, killing its king and wreaking havoc upon Baekje citizens. The devastating warfare continued on for 200 more years, and at various points many people of Kaya and Baekje fled, sailing across the sea for a new home. They came in several waves, and the Japanese archipelago was the most logical direction of flight not only because of its close geographic proximity but also because of Korea's longestablished contacts there since Jomon and Yayoi times.

As recorded in the Nihon Shoki (IX:10) (sometimes translated as The Chronicles of Japan, the second oldest book of classical Japanese history), to the leaders of Kofun Japan, the Korea Peninsula was known as "a land of gold and silver ... precious treasures dazzling to the eye." The Japanese for several centuries had been coveting and trading for Korean goods, especially for the iron tools and iron ingots of Kaya and Baekje, so the Korean immigrants and what they brought were welcome. Furthermore, the people of Kaya and Baekje had become Japanese friends and allies, going back to the time when the Baekje court invited Wa (Japanese) leaders to join them in the war against Koguryo, those fierce northern warriors intent on expanding southward. In A.D. 399, Baekje, Kaya, and Wa had formed an alliance for joint response to Koguryo's challenge. But, as already mentioned, the following year Koguryo forces dealt a lethal blow to Kaya and Wa in battles fought in the vicinity of modern Kimhae. In several other military ventures that followed, Wa, Kaya, and Baekje again suffered miserably at the hands of Koguryo's heavily armed and mounted cavalry. So in a real sense, the people of Kaya, Baekje, and Wa were linked by their histories as comrades in arms and fellow sufferers. That was another reason why the welcome mat was spread out to the people of Kaya and Baekje in their times of trouble and flight.

As people from Kaya and Baekje settled in the Japanese archipelago, they put to use all the knowledge and skills they had brought with them-for themselves, for previous immigrant communities they joined, for their Japanese neighbors, and particularly for the local Japanese elites who were eagerly seeking new skills and technology in their competitive relationships with other local and regional leaders (Kameda 2003a :1-14, 2003b:55-65, 2005:1-16).

In an exhaustive study on the new cultural elements that appeared in Japan during the Kofun period, Farris (1998:68-69) lists a great number of items and institutions. They include iron-working technology and products (swords, spear points, arrowheads, iron armor and helmets, horse trappings, hoes, spades, sickles); dam-building technology and stamped earth construction techniques; wheel-thrown, high-fired stoneware ceramics; gold and silver aristocratic accoutrements; silk weaving; a complex system of writing; methods of statecraft; a court ranking system; systematic units of measurement; Buddhist religion; and Chinesestyle law codes, to name only the most important.

\section{The Korean Factor in Japan's Transformation during the Middle Kofun Period}

Archaeologically, these new cultural items appeared suddenly in the tombs of Middle Kofun, often in lavish quantity, beginning around A.D. 400, and continued throughout the Kofun period. Their appearance was epochal and revolutionary. Clearly, Japanese society was changing, and there is today a broad consensus among Japanese and Korean archaeologists and historians that Korean immi- 
grants were key agents of sociocultural transformation in the emergence of regional military and political powers and ultimately state formation (Otsuka 1992:50-68; Shiraishi 2004:7-13; SPACAM $2001: 2-49$ ).

For example, during the Kofun period a kind of pottery known in Japanese as sueki became prominent in aristocratic burials throughout Japan (see Fig. 7). Sueki vessels were the prestige ware of the elite classes during the Kofun period and included mounted dishes, covered dishes, jars, bowls, and high pottery serving stands. Every aristocratic Kofun grave contained sueki-often in abundance. This was the industrially manufactured, wheel-thrown, high-fired stoneware made widely in Korea and known there as dojil togi, which came into Japan after the Koguryo invasion of the Kaya area in A.D. 400. As previously mentioned, one of the effects of Koguryo's devastating attack was to drive many Kaya people to leave the region, and according to Shin and Kim (2000:191-193), "The emergence of sueki pottery in Japan was essentially a reestablishment of southern Kaya pottery technology.... There is no room for any doubt about the connection between the two.... When Gumkwan Kaya was destroyed by Koguryo forces in A.D. 400 , the people of Southern Kaya states migrated to the archipelago." It is also a widely held consensus among Japanese archaeologists and ceramic specialists that the sue ware could not have developed in Kofun Japan without the Korean dojil ware specialists and their on-site technological contributions (Sadamori 1997: 167-176).

In Kyushu, Asakura sueki production was carried out at the Iyashiki, Ehime, and Ichiba Minami Gumi sites. Sueki was made at the Okugatani site in Okayama Prefecture and at the Suemura site in the Osaka region. The oldest sueki pottery from the Obatera workshop near Suemura closely resembles the dojil togi of the Busan and Kimhae areas in eastern Kaya, while the sueki from the Asakura workshops in Kyushu resembles that made in the western Kaya area (Takesue 1998:93-126; see also Barnes 1988:257). While Kaya technology was clearly dominant in the development of the sue ware from early on, Baekje and the Yeongsan River region in southwest Korea also contributed to the sueki repertoire along the way (Sakai 2004).

By about 450 A.D., the Suemura workshop in Osaka emerged as the dominant sueki production center in the Japanese archipelago, as it came under the control of the Yamato elites. Sueki vessels produced at Suemura were distributed to regional power centers, even as those areas produced their own pottery for local uses. For nearly a century, sueki vessels were used predominantly by the elite classes and buried in their graves, but by the early 700 s they became part of ordinary people's daily lives as well. The Suemura manufactory was continually operated until the $800 \mathrm{~s}$, and the pottery tradition itself persisted into the $1100 \mathrm{~s}$ (Takesue 1997:87-119).

Iron technology and production is another key industry that illuminates very well the activities and Korean connections of the Kofun period aristocracy in Japan. From the early 400s until the middle 500s A.D., Korean iron ingots were the Kofun period power elites' most sought-after trade item. An example is the trove from Yamato Rokugofun in Nara, a tomb classified as "king's tumulus type" and dated around 450 A.D. Its burial offerings included 872 iron ingots, 134 iron sickles, 139 iron hoes, 102 iron axes, 284 small iron knives, and 9 iron arrowheads, among other items (Azuma 1999:152-163).

Iron was long directly imported from Korea (Barnes 1988:257; Fujio 
2000:96-103), but local iron workshops were also established by Korean artisans who had fled Kaya after the Koguryo invasion of A.D. 400, as well as by Baekje immigrants (Azuma 1999:419-438). In northern Kyushu, such workshops have been identified at Hakata and the Juryu site. Kaya immigrants played a critical role in establishing extensive iron industries in the Okayama area (Kameda 2000:165-184). Large-scale iron workshops at Furu and Ogata in the Osaka plain also contain evidence that they were operated by Kaya immigrants (Kitano 1989:105-123; Takesue 1997:87-119). Locally produced iron implements included farm tools, weapons, and horse gear (stirrups, bits, and saddle parts) and were similar to those of Kaya.

As in the case of sueki pottery, standardized iron-plate body armor suddenly appeared during the Kofun period, strongly indicating that its technology moved to Japan from Kaya along with sueki technology (Jeong and Shin 1984:289-297; Kim and Song 2003:313-346). Soon, local production of cuirasses got under way, enhanced by the technology of riveting, also introduced from Korea in the fifth century A.D. Locally made cuirasses consisted of triangular plates or horizontal bands riveted together (Yoshimura 2000:104-111). In Korea, on the other hand, plate armor was discontinued, as newer and more practical lamellar armor became increasingly popular. It was subsequently introduced to Japan in the latter part of the fifth century (Kim and Song 2003:313-346; Shin 2000:261-276; Yoshimura 2000:105-111).

As critical as Kaya immigrants were in the development of iron industries and that of sueki pottery, the role of immigrants from Baekje was even greater and more critical to cultural and sociopolitical transformation in Kofun Japan. A number of elite as well as skilled Baekje citizens migrated to the Kyoto-Osaka-Nara region as early as A.D. 400, when Koguryo invaded Baekje territory and captured 64 Baekje fortresses between A.D. 396 and 407 (T. Tanaka 2001:2-23; cf. Nihon Shoki X:9-14). Major migrations of Baekje people into Japan, however, took place 75 years later, also as the result of Koguryo military actions. As noted earlier, after a long history of battles with Baekje, Koguryo in A.D. 475 finally succeeded in destroying the Baekje capital at Poongnap, in the Seoul area. When their capital fell, Baekje leaders, officials, noblemen, scribes, and skilled craftsmen fled south along with many of its inhabitants. Most stopped at Ungiin (modern Gongju), where they built a new Baekje capital, but some, like the Kaya people before them, sailed to Japan, with which the Baekje court already had friendly relations.

The majority of Baekje immigrants settled in the Kyoto-Osaka-Nara region, mainly in the Kawachi plains and the southern Nara basin. There they engaged in sueki pottery industries. They also undertook the first large-scale canal- and dam-building projects to drain the Kawachi wetlands for agricultural expansion, critical to the growing Yamato power. According to recent archaeological investigations at the Kamei and Kyuhoji sites in Osaka, during Early and Middle Kofun periods, Baekje immigrants built dams and dikes around Kawachi Lake, employing Baekje pounded earth and dam construction technology-known as buyeop gongbeop - which entailed spreading multiple layers of organic materials and tree leaves at the base of a dam or a dike (Koyamada 1991:94-97, 2003:371-385; Shirai $2001: 81-82$ ).

Baekje immigrants also established the first horse-raising farms, as well as horse- 
driven transportation, in Kawachi (K. Mori 2001:130-133; Osaka Museum of Yayoi Culture 2004:48-49; K. Tanaka 2004:88-95). In light of an account in the Nihon Shoki (XVII:2) regarding a person named Arako, the leader of a horseraising farm in Kawachi and a close friend and supporter of Emperor Keidai, Mori Koichi (2001:130-133) posits that the support of the Baekje immigrants in Kawachi was critical to Keidai's (A.D. 507-531) ascension to the Yamato throne. This was necessary because whoever sought to have an upper hand militarily and politically in the Japan of this period had to depend on horses and horse-driven transportation, the new technological innovation of the day, and it was the Baekje immigrants of Kawachi who had just begun to develop it. Throughout the 500s, the horse, with all its gilt-bronze trappings of Korean origin, also became the symbol of socioeconomic status and political power.

\section{STATE FORMATION IN ANCIENT JAPAN (C. A.D. 5O0-6O0)}

In this section, we present historical and archaeological syntheses of Baekje's contributions to the emergence of Yamato State and its aristocratic culture, as well as its brilliant Asuka era. Discussed also are the roles played by Korean immigrants and their descendents as powerful technocrats and political functionaries in the Yamato court.

\section{Baekje's Cultural Mission to Yamato}

Beginning early in the 500s, the state of Baekje embarked upon a systematic path of planting Baekje culture in the heart of Yamato as its official policy. According to the Nihon Shoki (XVII:11, 17), in A.D. 513 and 516 Baekje king Muryeong (A.D. 501-523), from the Baekje capital at Ungjin (Gongju), sent to Yamato king Keidai teachers of Chinese writing and Confucian scholars. An ability to read and write would equip managers and administrators with recording and communication skills essential to their job performance. Learning in the Confucian classics would acquaint government leaders with the primary Chinese texts for wisdom and knowledge in administration and statecraft.

In A.D. 552, King Seong (A.D. 523-554), from Baekje's new capital at Buyeo, sent high-ranking officials to the Yamato court along with Buddhist sutras, a statue of the Buddha, and various other items of religious paraphernalia to promote Baekje Buddhism in Yamato. Two years later, Baekje king Wideok (A.D. 554598) sent another expert in Confucian classics, a great Buddhist priest named Damhye, and eight other priests. This group also included a specialist in the calendar, a physician, an herbal specialist, and a musician (J-K. Roh 1988:224262). Again in 577, Wideok sent temple architects and builders of pagodas, along with priests.

In A.D. 587, the Yamato court in Asuka, under the leadership of Soga Umako, a powerful descendant of a Baekje immigrant, adopted Buddhism as its official religion (Nihon Shoki XXI:6). It would provide the Yamato leaders ethical values and a spiritual foundation with which to unify the people and the nation. With Buddhism also came new art and architecture, which would define Japanese art and architecture for a millennium or more.

As soon as Baekje Buddhism became the official religion of the Yamato court, Baekje king Wideok dispatched to Asuka three high-ranking officials, 12 Bud- 
dhist priests headed by Hyechong, two temple architects, one temple metal smith, four specialists in roof tile manufacturing, and one Buddhist art painter to help construct Japan's first Buddhist temple. The temple was completed in 596 and was called Hokoji; it was also known as Asukaji (Nihon Shoki XXI:13, XXII:3). Soga Umako then appointed his son as the head of the temple and Hyechong and Hyeja, renowned priests from Baekje and Koguryo respectively, as resident priests. Hokoji Temple was the first edifice ever constructed in Japan with stone foundations and roof tiles, and archaeological excavations of the temple site have revealed that the roof tiles of Hokoji-as well as those of all early Buddhist temples in the Kyoto-Osaka-Nara area-were local versions of Baekje tiles manufactured by Baekje tile specialists (Fig. 10). With the arrival of Baekje Culture, its

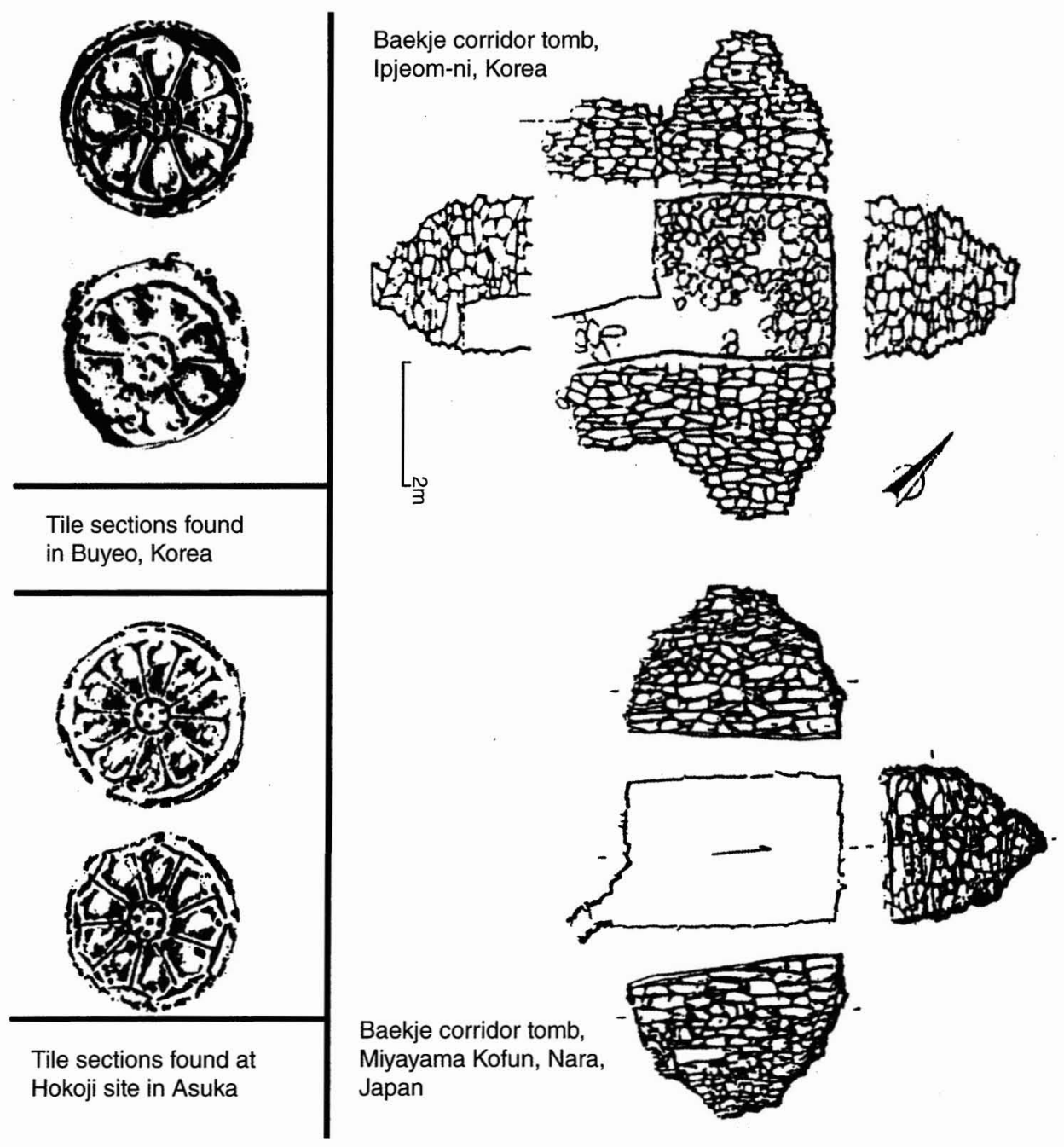

Fig. 10. Left: Decorated end sections of "male" roof tiles of Baekje (after Gongju National Museum 1999:50); right: Baekje corridor tombs (after W-K. Choi 1997:230; Yoshi'i 2001:116). 
arts, its architecture, and its Buddhist religion, Kofun Japan entered the Asuka era, the most brilliant cultural period in ancient Japan.

In the Chikatsuasuka area, corridor tombs of Baekje type dot the landscape, many of which undoubtedly belonged to the Baekje immigrants. Beginning early in the 500s, Yamato elites of the Kyoto-Osaka-Nara region adopted Baekje corridor tomb construction for the burial chambers of traditional Japanese keyhole tombs (see Fig. 10). By the end of the 600s, corridor tombs became the predominant form in the region, replacing the keyhole tombs altogether (Kawakami 2000: 93-101). Furthermore, as in Baekje, the corridor tomb type of construction carried political overtones, as it defined relationships between the Yamato central government and local power elites (Yoshi'i 2001 : 104-117).

The southern part of the Nara basin, the heart of Yamato power, had long been a major center of Korean immigrants. This is evidenced by numerous tombs of Kaya and Baekje style, along with distinctly Korean yeonjil pottery types, including portable miniature cooking ovens made of pottery (Kashihara Archaeological Institute Museum 1999:70-73; Sakurai City Buried Cultural Property Center 2005:2-13). The Nango site in Katsuragi was a major industrial center operated by skilled Korean immigrants who produced a variety of wrought iron implements, copper and silver artifacts, and glass jade ornaments, along with long iron swords, using an advanced bellows system. Archaeological remains of traditional Korean potteries, abacus-shaped spindle whorls, and residential buildings of Korean type indicate that Nango was a base for Korean craftsmen as well as local leaders of Korean origin (SPACAM 2001:37). Tomb 126, among the group of Shinzawa Senzuka tumuli of Korean type, located near Kashihara, has yielded an impressive array of precious goods of Korean origin, including gold ornaments, gold earrings, glassware, and iron body armor. The tomb is believed to have belonged to a powerful member of the Korean immigrant community (SPACAM $2001: 32)$.

\section{Technocrats and Political Functionaries of Korean Origin}

Among the Korean immigrants of the southern Nara basin, the Aya and the Soga clans were the most prominent during the Kofun period and even long after. Coming from Ara or Aya Kaya (modern Haman in southern Korea), the Aya clan, consisting of Ara Kaya elites, settled in the Hinokuma area of the Nara ba$\sin$. In time, they came to control various be (a system of functional groups), producing iron weapons, iron body armor, iron horse gear, sueki, and gold and silver craft, as well as high-quality fabric and silk industries (Suzuki 1995:58-59; cf. Yamao $1997: 49-50)$. In time, many Aya clansmen became high-ranking military leaders and officials in charge of translation, official documents, and foreign affairs (Suzuki 1995:58-59; Ueda 1991:61-66). When the Yamato court initiated formal cultural missions to Sui China early in the 600s A.D., Korean immigrants and their descendants acted as the main protagonists (Nakamura 1981:96-97).

The Soga clan dominated Yamato state affairs for nearly a century, from about A.D. 550 to 650 , the most defining period in the formation of the Japanese state. The Soga clan originated among Baekje immigrants, specifically from Mokra Manchi, or Soga Manchi as he became known in Japan. Manchi was an important Baekje official and confidant of Baekje king Gaero (A.D. 455-475) when the 
Baekje capital was still in Seoul. In the aftermath of Koguryo's sacking of Seoul in A.D. 475, Manchi joined the Yamato court in Nara as Baekje began to develop close relations with Yamato from its new capital at Ungjin (Kadowaki 1973:7991, 1991:169-212; E-S. Kim 1992:17-42; T. Tanaka 1992:92-98; Yamao $1977: 31-36,1989: 155-56)$. In the course of time, his descendants changed their family name to Soga, after the name of the place where they settled (in modernday Kashihara), as was the custom of the day (Kadowaki 1973:88), and Manchi's name in the annals of Japanese history became Soga Manchi.

Soga Manchi's father, Geunja, was a Baekje general and he himself had been active in Baekje's relations with Kaya (Nihon Shoki IX:28, X:17). Such a background plus his own experience in the Baekje government made him a valuable asset to the Yamato court, especially in matters related to Baekje, Kaya, the military, and finance. He worked his way up in the Yamato court, becoming minister of finance and establishing personal relationships with the king and elite members of the court. By the time of Manchi's great-grandson Soga Iname and his son, Soga Umako, the Soga family had established a close relationship with the reigning king through marriage. Soga Umako, after crushing the rival Mononobe clan, emerged in A.D. 587 as perhaps the most powerful functionary in the Yamato government. He became allied with Prince Shotoku in the establishment of Baekje Buddhism as the official religion of the Yamato court, and together they took political, economic, cultural, and military actions in the advancement of the Yamato state.

In the meantime, the Hata clan, a powerful elite class from the Uljin area of ancient Shilla, settled in the Kyoto area around A.D. 450 after Shilla came under Koguryo control. Soon, as part of the Yamato ruling elite, the Hata family organized Korean immigrant communities, particularly those of Kaya, for industrial production needed by the Yamato court (Suzuki 1995:57-58). With superior engineering skills, they also built dams and dikes around Kyoto to drain and develop the Kyoto plains for agricultural expansion, and by A.D. 500 they emerged as the wealthiest and most powerful elite in the entire Kyoto basin (Yamao 1977:43-46). With their wealth, the Hata clan built numerous temples and shrines in Kyoto, including Fushimi Inari Shrine, Matsuo Shrine, and the Koryuji Temple. They also formed a marriage alliance with the powerful Fujiwara clan, thereby exerting enormous influence in the Yamato government (Kyoto Cultural Museum 1989:131). Beginning around A.D. 540, they also became closely allied with the Japanese imperial family and played a decisive role in the rise of Prince Shotoku as the supreme Yamato statesman (Yamao 1977:46-47; cf. M. Inoue 1991:81-130; Ueda 1991:66-71). It should also be noted that in Emperor Kanmu's moving the Yamato capital from Nara to Nagaoka-kyo and eventually to Heiankyo in Kyoto in A.D. 794, the Hata clan played the primary supportive role in finance and engineering (Kyoto Cultural Museum 1989:131).

The presence of numerous Korean immigrants in the Kyoto-Osaka-Nara area during the Kofun period is evidenced in both ancient records and recent cranial comparisons. According to the Shoku Nihongi (Hoki, Year 3) (an imperially commissioned history of Japan written in the early Heian period), the southern Nara basin, which was the heart of Yamato power, was filled with Korean residents in A.D. 773. Of the entire population of the area, 80-90 percent claimed Baekje origin. This historical account is further supported by cranial analyses link- 
ing modern Japanese of the Kinai (Kyoto-Osaka-Nara) region closest to modern Koreans among all Japanese population groups (Hanihara 1984:192-198, 1990:70-82).

Besides the Kinai area, a large number of Korean immigrants also settled in the Kanto region, north of Tokyo. In Gumma, they operated extensive horse-raising farms as well as advanced metallurgical factories, producing horse transportation gear, gold ornaments, and a variety of iron tools. In the 500s, some of them emerged as powerful local chieftains, building for themselves large stone piled tombs as well as zempo koen-type tombs such as the Watanuki Kannonyama and Hachiman Kannonzuka kofun. Discovery of a bronze mirror in the Watanuki Kannonyama Kofun that is identical to one found in the tomb of Baekje king Muryeong, strongly suggests a close tie between Baekje and the Kanto region as well (SPACAM 2001 :74-83). Thus, among Korean immigrants were carpenters, ironsmiths, ceramic specialists, skilled craftsmen in gold and silver, artists, public works engineers, scribes, learned scholars, priests, warriors, aristocrats, and skillful elite organizers and leaders. They and their descendants provided Japanese society with goods and know-how it needed in the management of business, in administration and governance, in the building of iron and other craft industries, in horse breeding, and in the advancement of transportation modes. Some immigrants and descendants of immigrants mingled with Japan's ruling elites, becoming pioneers and leaders in the early formation of the Japanese state.

\section{Yamato Hegemony, New Political Institutions, and Prince Shotoku}

During the 400s A.D., leaders in the Kawachi plain, which was the center of Korean immigrants from Kaya and Baekje, rose to paramount status in the area. The monumental tombs of Kondayama and Daisen that exist there are evidence of this. Clearly the burial places of very powerful leaders, these huge keyhole-shaped mounds are generally cited as indicators of the emergent Yamato hegemony (Barnes 1988:279-281; Yamao 1977:38-71). The specific conflicts and negotiations that led to Yamato dominance throughout Japan continue to be explored, but the Nihon Shoki shows clearly enough that the primacy of the Yamato house had been at least incipiently established by about A.D. 530, following the incorporation of Katsuragi and Kibi into Yamato hegemony and the defeat of Kyushu forces led by Iwaii, and with that the process of state formation began (Kamada 1986: 41-91; Yamao 1977:69-75, 1998:129-132).

A key political necessity was making the Yamato kingship a hereditary system, and for that purpose rituals of kingly succession were formalized that closely followed Baekje practices. Also incorporated into the Yamato kingship ideology was the concept of its origin from heaven (or the sun), so as to assure its importance and permanency (Yamao 1977:72-74). Another critical development was the transferring of all political powers to the Yamato court by bringing the local power elites under its umbrella. Members of local elites were appointed as officials of the central government, now linked into the Yamato aristocracy with ranks and titles. The Yamato court sought to maintain these officials' loyalty by awarding gifts of special value that were either imported from Korea or made locally by Korean craftsmen (Yamao 1977:91-93).

In A.D. 535 a series of 26 miyake-essentially military garrisons and granaries- 
was established throughout western Japan to control all regional powers. These were placed close to the seats of potentially troublesome local powers and in various strategic locations such as harbors, transport routes, and waterways (Vargo $1982: 75)$. Thus they were placed under the supervision of local leaders loyal to the Yamato court, and in certain cases an official from the Yamato court was dispatched to a miyake. Inasmuch as operation of miyake required literate bureaucracy, Korean immigrants, especially those from Baekje, assumed various administrative responsibilities (Kamada 1986:133-142).

Also, be-functional groups inspired by the $b u$ bureaucratic system of Baekje (Barnes 1988:272; Kamada 1986:92-120)-were articulated to control local populations, to facilitate economy and industry, and to organize farmers, artisans, and laborers in the service of the central government or local managerial elites. "The most important aspect of the be was not what was produced by the be. More important was the political character of the system. Yamato tried to gain control over areas resisting its influence by the establishment of institutions like be and miyake" (Vargo 1982:69).

As previously noted, to enhance the unity of the nation and its people the Yamato court adopted Buddhism from Baekje and built Buddhist temples. It also learned from Confucian scholars and statesmen of Baekje much about the art of government, political organization, and duties of rulers and subjects. In A.D. 603, Prince Shotoku established a 12-rank system for Yamato officialdom, each rank represented by a particular color, as it was in Baekje, and the following year he proclaimed the Seventeen Article Constitution, which would define the character of the Yamato state both socially and politically. Japan was now entering a new chapter in the history of its civilization, a thousand years after prehistoric Korean farmers arrived in northern Kyushu and settled in with the local people.

\section{Epilogue: Historical Baekje and theYamato State}

Baekje's close ties with the Yamato court continued on unabated even after the proclamation of the Seventeen Article Constitution in A.D. 604, to such an extent that in A.D. 639 Emperor Jomei (629-641) built a great palace and an impressive pagoda by a river named Baekje River (also called Soga River), and he named it Baekje Palace, taking residence there. When he died the following year, an imperial resting hall was constructed next to the Baekje Palace, and it was named the Great Baekje Hall (Nihon Shoki XXIII:14-16).

In A.D. 660, Baekje was invaded by the combined forces of Shilla and Tang China. As Baekje's troops suffered devastating blows in the battlefields and the capital city at Buyeo lay in ruin, the Yamato court dispatched 27,000 troops in A.D. 663 across the sea to assist Baekje. After a few days of battle, however, the Yamato troops were completely routed and destroyed by the Tang navy. That sealed Baekje's fate as a nation, and all high-ranking officials, generals, and members of the Baekje nobility not killed or captured by Tang forces, numbering several thousand, crossed the South Sea toward Yamato, along with learned scholars, Buddhist priests, skilled craftsmen, and ordinary citizens. It was a massive and wholesale migration of the finest and the best of the Baekje nation into Japan.

Once in the Kyoto-Osaka-Nara region, about 2400 of the refugees were located in areas where Korean immigrants of earlier days had carved out their 
"colonies," such as Omi in Shiga Prefecture and the Gumma region north of Tokyo in eastern Japan (Nihon Shoki XXVII:11-13). (It is noteworthy that Omi was also Emperor Keidai's original home base.) Others, including scholars, priests, scribes, and generals, settled in the Kyoto-Osaka-Nara area and served the Yamato court in various official capacities. Surviving members of the Baekje royal family settled in Naniwa in the Kawachi area, a major center of earlier Baekje immigrants, in close relationship with the Yamato ruling family (Furuichi 2001:118-125). Those who had served as high-ranking officials in the Baekje court were granted various ranks of Yamato nobility and invited into the service of the growing Yamato state. The infusion of such a large pool of experienced statesmen, generals, scholars, priests, technicians, and artists to the Yamato court, which was still in its infancy as a full-fledged state, was a boon of incalculable value that helped the new nation mature even more. In A.D. 670, the Yamato court adopted Nihon- "Land of the Rising Sun"-as its formal name, and the nation we know today was officially born.

\section{CONCLUSION}

In this article, we have focused on Korean contributions to the growth of sociocultural complexity and state formation in ancient Japan during a formative thousand years between about 400 B.C. and A.D. 600. We have demonstrated through archaeological evidence and ancient historical texts that many of the cultural, technological, and ideological elements involved came directly from Korea.

The epochal thousand years of this formative period in Japan followed a long developmental period that began in Korea as early as 1500 B.C., when mixed farming became progressively established throughout the peninsula. By 700400 B.C., Korea's Songguk-ni and cognate cultures were flourishing in both small and large village communities, many of the latter surrounded by a moat and some also containing a smaller moated precinct within. Their people were growing paddy field rice and other cultigens, including wheat, barley, foxtail millet, Chinese millet, beans, peas, and perilla (sesame), often storing their harvest in large centralized structures that were elevated on posts.

Around 600-400 B.C., a time in Korea of rapidly growing population, the emergence of elite districts within communities, apparent social conflicts, increasingly prevalent fortifications and moats surrounding those communities, and increasing devastations of settlements by fire, a number of sites sharing key Songguk-ni characteristics appeared in Japan around Kyushu's Hakata and Karatsu Bays, which face the narrow Korea Strait. Manifestly, emigrants were encouraged to embark by the political and economic stresses growing within Korea and by the obvious opportunities presented by readily cultivable land in nearby Japan that was only lightly populated by Jomon hunter-gatherers. Certainly both the organizational experience and the motivation required to "bud off" new settlements were available in Korean communities of the time.

Skeletal data from the new Japanese farming sites, now archaeologically referable to the Yayoi Culture, show that the Korean immigrants promptly began intermarrying with local Jomon people. Communities grew and multiplied rapidly, and the high rate of population expansion supported by the new farming economy, as well as some continuing Korean immigration over centuries, assured 
a substantial Korean infusion into the preexisting Jomon gene pool that gives the Japanese population its distinctive dual structure today.

During the long period between 400 B.C. and A.D. 400, Korea made technological improvements in bronze, iron, and ceramic industries, initially through its connections with Manchuria and later (around 100 B.c.) through the Han Chinese outposts at Lolang and Taifang in northwest Korea. Beginning early in the first century B.C., the Korean Bronze Age began to decline as iron tools and weapons became increasingly more valuable for agricultural expansion and emerging military elites. By the 100s A.D., Korea developed local iron foundries and began to produce prodigious amounts of iron tools for agricultural and military purposes. Also, by the beginning of the Christian era, the low-fired, hand-made, plain coarse pottery of the Songguk-ni and the Late Bronze Age culture was gradually replaced by high-fired, wheel-thrown, grayish-blue pottery, and by A.D. 250, dojil (stoneware) pottery had emerged as Korea's new pottery form.

Korean bronze technology spread to Kyushu in southern Japan during the Early Yayoi period with Korean immigrants, and by the Middle Yayoi period the latter had helped develop thriving bronze industries in northern Kyushu. When bronze production ended in Korea at the beginning of the Christian era, Kyushu elites acquired Chinese bronze mirrors through the Chinese trading posts at Lolang and Taifang, as well as trading posts along Korea's southern coast, and had them copied locally. As for iron tools, they were imported into Japan largely from southern Korea for nearly 700 years, from 200 B.C. to A.D. 500, until Korean immigrants helped develop in Japan local foundries in the 500s A.D. Shortly after A.D. 400, the sueki pottery industry - the Japanese version of Korean dojil (stoneware) pottery - appeared also under the influence Korean immigrants.

In Japan as in Korea, these industries were developed within societies of growing complexity. They served most directly the needs of local elites for high-value symbols to reinforce their elevated socioreligious standing and, increasingly over time, for effective tools of economic production and military force.

Throughout the Yayoi and Early Kofun periods, the Japanese society remained largely agrarian and ritualistic, even as their political power continued to grow and chiefly burial tumuli of monumental size began to appear in the Nara region. This changed about A.D. 400, however, with an accelerating appearance in Kofun burials of Korean-made iron and steel weaponry, horse trappings, body armor, and other indicators of military contention among the regional Japanese elites.

The appearance of these new elements in Japan coincided with a calamitous upsurge of warfare on the Korea Peninsula-following the collapse of Chinese outposts in Lolang and Taifang (A.D. 313-314)-among the kingdoms of Koguryo and Baekje, and later Shilla and the Kaya states. On several occasions these wars also involved armies sent to the aid of Baekje and Kaya from Japan, which had long-standing trading interests in southern Korea. Disastrous military reverses on several occasions sent pulses of fleeing Baekje and Kaya aristocrats and their households-including generals, soldiers, and managers, along with ironworkers, horse breeders, and other kinds of skilled artisans-into Japan, where whole communities were given sanctuary as allies.

Archaeological evidence shows that Korean groups moved into the Inland Sea region as far as Okayama and beyond and concentrated in the Osaka-Kyoto- 
Nara region. Over succeeding generations, like their Yayoi predecessors, they became naturalized Japanese. Thus did incidents of warfare in Korea bring to the leaders of Yayoi-developed Japanese polities both the tactical knowledge and the technical underpinnings of a new basis for consolidating and expanding their power-namely, mounted cavalry and soldiers armed with iron and steel weapons.

Throughout the later 400s and 500s, mounted warfare was a major instrument of the process by which many small polities of Yayoi and Early Kofun period Japan gradually coalesced into fewer and larger power centers and by which powerful allied forces of the Osaka-Kyoto-Nara region, including some Japanese descendants of earlier Kaya and Baekje refugees, finally accomplished the political unification of central and southern Japan in the Yamato state. As this process was going on in Japan, warfare continued in Korea, culminating in the brutal crushing of Baekje between the pincers of Shilla and Tang China in A.D. 660, which left the whole peninsula under the control of Unified Shilla. Japanese forces were sent to the aid of Baekje-but to no avail. The decisive defeat sent a final pulse of Baekje aristocrats into Japan, where they settled among their Yamato allies in the Osaka-Kyoto-Nara region. Ultimately, the flavor of Yamato's aristocratic culture, organizational structure, and Buddhist religion owed much to the traditions and statecraft bequeathed to Japan by Kaya and Baekje survivors who had trickled into the country over centuries.

Finally, our review of the accumulated archaeological and historical evidence solidifies a new perspective on two highly controversial issues germane to the main themes of this article: the theory of Mimana Nihonfu and the theory of the conquest of Japan by horse-riding armies from Korea. Strongly advocated in prewar Japan (Suematsu 1949) and long echoed in Western literatures (Hall 1970:37-43; Murdock 1910; Reischauer and Fairbank 1958:468-469; Sansom 1962:33-35), the Mimana Nihonfu theory held that the Yamato government conquered southern Korea in the 300s A.D. and established a military base called Mimana Nihonfu in Kaya territory on Korea's southern coast. The Yamato state, according to the advocates of this theory, used the base for 200 years to acquire advanced Korean culture as well as to promote its interests in the peninsula. In our study we have found no credible evidence-archaeological or historical-to support this theory. Japan had been growing steadily in its sociopolitical complexity, but during the Early Kofun period it still had no central government and its society was strongly agrarian. It imported iron from Korea and lacked mounted soldiers. It was not in a position-politically, militarily, or technologically-to conquer southern Korea, which was home to the powerful kingdoms of Baekje and Shilla, as well as numerous Kaya states fortified with iron weaponry and mounted cavalry. In addition, there was Koguryo in the north, ready to crush any form of Japanese (Wa) military impingement on Korea, as it did in A.D. 400 and in subsequent years. As understood by most modern Japanese scholars, Mimana Nihonfu is no more than a political tall tale created by the growing Yamato court of the 700s, built on the unquestioned existence of Japanese trading posts on Korea's southern coast and on military alliances between Kaya, Baekje and Japan (then called Wa) that had indeed functioned during the 400s and 500s.

Nor have we found evidence to plausibly support a conquest hypothesis of a totally opposite nature, initially proposed by Egami (1967) and subsequently sup- 
ported by Ledyard (1975) and others (Hong 2006). According to Egami, from quite early times various peoples from northern Asia, including seminomadic horse riders, had been moving into the Korea Peninsula. Early in the Christian era, one such group, known as the Buyeo and closely related to the Koguryo people, arrived in the Korea Peninsula from eastern Manchuria. Some of their elites established the kingdom of Baekje in the Seoul area during the 200s A.D., while others established the kingdom of Jin in the Jinhan-Byunhan area on the southeastern coastal area. As Koguryo began to emerge as a powerful kingdom in the north around A.D. 300 and Baekje and Shilla were doing the same in the south, the Jin state changed its name to Imna Kara (Kaya) (Japanese Mimana). At the same time, according to Egami, under the shadow of the rising powers the horse riders of the Jin state began to feel insecure, and some of their elites decided to move into the Japanese islands. They began by conquering northern Kyushu in the early 300s and creating a "Wa-Korea United Kingdom," formed out of invading Jin state warriors, local Kyushu elites, and Kaya forces in Korea. Decades later, around A.D. 400, horse-riding warriors of the United Wa-Korea Kingdom conquered the Osaka-Kyoto-Nara region and immediately created the Yamato state, first in Kawachi (modern-day Osaka) and later at Asuka in the Nara basin. A more recent variant of Egami's hypothesis, advocated by Hong (2006), argues that Japan was invaded and conquered by the state of Baekje rather than the Jin state in Kaya. He supports this argument by reinterpreting sections of the Nihon Shoki that pertain to Baekje-Yamato relations.

There is an extensive critical literature on Egami's theory for readers interested in knowing more about it (Mizuno 1975; Sahara 1986), but our reading in that literature leads us to share the skepticism of the theory's critics. We believe that a more accurate picture of Korean-Japanese relationships has emerged from the broad base of archaeological evidence and historical interpretation that has become available since Egami formulated his ideas, and it is not a picture of conquest but rather one of peaceful interaction between the populations of Kaya/Baekje and those of Japan, for mutual benefit and taking place over many centuries, which began with the first rice farmers and reached a later plateau with the arrival of a final group of refugee Baekje aristocrats in Japan during the 600s. We trust that additional light will be shed on these interactions by future advances in archaeological and historical research.

\section{ACKNOWLEDGMENTS}

In the course of our research, we received invaluable assistance from numerous scholars in Korea and Japan, and special thanks are due the following (in alphabetical order): in Korea, Seung-ok Baek, Mong-lyong Choi, Wan-kyu Choi, Bo-sik Hong, Yeong-rae Jeon, Gu-geun Kim, Seong-gu Kim, Seung-ok Kim, Jang-geun Kwak, Jae-hyun Lee, Jong-cheol Lee, Joong-hwan Park, Kyeong-cheol Shin, UiJeong Song, and Duk-hyang Yun; in Japan, Hirakori Tatsuya, Hirose Yuichi, Kameda Shuichi, Kinoshita Wataru, Kohama Sei, Koyamada Koichi, Matsumoto Kazuo, Nishitani Tadashi, Tanaka Toshiaki, Tomioka Naoto, and Yoshi'i Hide. We are also greatly indebted to the archaeological staff of various museums and research institutes for generous assistance provided during our research: in Korea, Baekje Culture Research Institute, Bokcheon Museum, Buyeo National Museum, Buyeo National Research Institute of Cultural Heritage, Daeseong-dong (Kimhae) Tumuli Museum, Gongju National Museum, Haman Museum, Kimhae National 
Museum, Kyeongju National Museum, and Poongnap Earthen Fortress Research Center; in Japan, Itokoku History Museum in Maebara City (Kyushu), Kashihara Archaeological Institute Museum, Okayama Ancient Kibi Cultural Research Center, Osaka Chikatsuasuka Museum, Osaka Yayoi Culture Museum, and Shiga Azuchi Castle Archaeological Museum. This work was supported by Korea Research Foundation Grant (MOEHRD) (KRF-2004-042-A0023).

\section{REFERENCES}

Note: Titles of publications in Korean and Japanese are translated into English and marked: $(\mathrm{K})$ publications in Korean, ( $\mathrm{J}$ ) publications in Japanese.

AHN, JAE-Ho

2000 Formation of Korean agiricultural society. Journal of Korean Archaeological Society 43: 41-46. (K)

Ahn, Seung-Mo

1998 Prehistoric Agriculture and Subsistence of East Asia. Seoul: Hakweon Munhwasa. (K)

Aikens, C. M., and Takayasu Higuchi

1982 Prehistory of Japan. New York: Academic Press.

Akazawa, Takeru

1982 Culture change in prehistoric Japan: Receptivity to rice agriculture in the Japanese archipelago, in Advances in World Archaeology: 151-211, ed. F. Wendorf and A. Close. New York: Academic Press.

AN ZHI-MiN

1985 Influence of the prehistoric culture of the lower reaches of the Yangtze River on the Japanese archipelago. Kokogaku Zasshi 70(3):297-311. (J)

Azuma, Ushio

1999 Ancient Asia's Iron and Wa. Hiroshima: Keisuisha. (J)

BABA, HisAO

1997 Jomonjin, in Jomon and Yayoi: 26-37, ed. Organizational Committee for the 11th Open Symposium on Higher Education and Science. Tokyo: Kuba Pro. (J)

BARNES, G. L.

1988 Protohistoric Yamato. Ann Arbor: University of Michigan.

1990 Early Korean states: A review of historical interpretation, in Hoabinhian, Jomon, Yayoi, Early Korean States: 113-153, ed. Gina Barnes. Oxford: Oxbow Books.

1992 The development of stoneware technology in southern Korea, in Pacific Northeast Asia in Prehistory: 197-208, ed. C. M. Aikens and Song-nai Rhee. Pullman: Washington State University Press.

2000 Archaeological armor in Korea and Japan: Styles, technology, and social setting, in Clashes of Iron: Arms, Weaponry, and Warfare in Early East Asian States: 60-95, ed. G. L. Barnes. Leiden: Brill.

BoKCHEON Museum

1996 Tumuli of Bokcheon-dong. Busan, Korea: Busan City Museum. (K)

1999 Ancient Warriors: Ancient Warriors and Weaponry. Busan, Korea: Busan City Museum. (K)

Busan University Museum, ed.

1995 Ulsan Geomdal-li Village. Busan, Korea: Busan University Museum. (K)

Chisholm, B., H. Koike, and N. Nakai

1992 Carbon isotopic determination of paleodiet in Japan: Marine versus terrestrial sources, in Pacific Northeast Asia in Prehistory: 69-82, ed. C. M. Aikens and Song-nai Rhee. Pullman: Washington State University Press.

Cho, Hyeon-Jong

2000 Emergence and development of rice farming, in Culture Change and Culture Contact in Ancient Korea: 3-30, ed. Hong-jong Lee. Seoul: Seokyeong Munhwasa. (K)

CHOI, ByEONG-HyEON

1998 The origin of wooden chamber tombs with piled stone mounds in Shilla. Soongshil Sahak 12. (K) 
CHOI, JONG-TAEK

1994 Misari settlement types and their changes, in Village Settlement Archaeology: 97-136, ed. Hanguk Gogohakhoe. Seoul: Korean Archaeological Society. (K)

Choi, Mong-Lyong

1992 Trade in Wiman state formation, in Pacific Northeast Asia in Prehistory: 185-190, ed. C. M. Aikens and Song-nai Rhee. Pullman: Washington State University Press. (K)

Choi, SeONG-RaK

1986 Yeong'am Jangcheon-ni Dwelling Site II. Mokp'o University Museum. (K)

1993 A Study on the Culture of Korea's Proto-Three Kingdoms. Seoul: Hakyeon Munhwasa. (K)

ChOI, WAN-KyU

2002 Jugumyo in the North Cholla region, in Jugumyo of East Asia: 19-45, ed. Honam Gogohakhoe. Gwangju: Honam Archaeological Society. (K)

Dongui University Museum

1988 Daeya-ri Settlement I. Busan: Dongui University Museum. (K)

Eckert, C., Ki-Baek Lee, Young-Ick Lew, M. Robinson, and E. W. Wagner

1990 Korea, Old and New: A History. Cambridge, MA: Korea Institute, Harvard University.

Egami, Namio

1964 Formation of Japanese People and the Origin of Japanese State. Tokyo: Tokyo University Press. (J)

1967 Horse Riders' State. Tokyo: Chuo Koronsha. (J)

FARRIS, W. W.

1998 Sacred Texts and Buried Treasures: Issues in the Historical Archaeology of Ancient Japan. Honolulu: University of Hawai'i Press.

Fujio, SHIN'ICHIRo

2000 The relationship between Kaya and Silla and western Japan in terms of iron production from the first century B.C. to the sixth century A.D., in Clashes of Iron: Arms, Weaponry, and Warfare in Early East Asian States: 96-103, ed. G. L. Barnes. Leiden: Brill.

Furuichi, AKIRA

2001 The royal family of Baekje and Baekje-gun, in Ancient Kawachi and Baekje: 118-125, ed. Hirakata Rekishi Forum Jikko I'inkai. Hirakata: Daikoro Co. (J)

GANG, HyUN-SOOK

2002 The appearance of Koguryo high mound tombs and Koguryo political development, in The Appearance of Large Ancient Tombs in East Asia and Social Changes: 1-23, ed. Munhwajae Yeonguso. Seoul: National Cultural Property Research Institute of Korea. (K)

Gongju National Museum, ed.

1999 Investigative Report on Baekje Culture Remains in Japan, I (Kinki section): 90. Gongju: Gongju National Museum. (K)

2002 Geumgang: The Last Ten Years of Excavations. Gongju: Gongju National Museum. (K)

GOTO, TADASHI

1986 Emergence of agricultural society, in Iwanami Lectureship Series: Archaeology of Japan No. 6: 120-169, ed. Iwanami Lectureship Committee. Tokyo: Iwanami Shoten. (J)

1987 Korean-made bronze implements and associated materials found in northern Kyushu, in Kobunka Danso: 8-16, ed. Fujio Oda. Kita Kyushu: Kyushu Ancient Culture Research Association. (J)

Gyeongju National Museum

1996 Shilla Tombs. Gyeongju: Gyeongju National Museum. (K)

HALL, J. W.

1970 Japan from Prehistory to Modern Times. New York: Delacorte Press.

Hanimara, Kazuro

1984 The Origin of Japanese. Tokyo: Asahi Shimbunsha. (J)

1990 New Theories on the Origin of Japanese. Tokyo: Kadokawa Shoten. (J)

1993 Ancient Japan conquered by immigrants, in The Original Japanese: The Riddle of Yayoi and Jomon People: 6-29, ed. Asai Shimbunsha. Tokyo: Asahi Shimbunsha. (J)

Harunari, Hideji

1990 Beginning of the Yayoi Period. Tokyo: Tokyo University Press. (J) 
Higuchi, TAKayasu

1986 Relationships between Japan and Asia in ancient times: Introductory comments, in Windows on the Japanese Past: Studies in Archaeology and Prehistory: 121-126, ed. R. Pearson. Ann Arbor: University of Michigan Center for Japanese Studies.

1995 Diffusion of rice cultivation from the Yangtze River Basin, in Origins of Rice Cultivation in East Asia and Ancient Rice Agriculture (in Japan): 282, ed. Kikuo Wasano. Saga City: Saga University Department of Agriculture. (J)

Hirose, Kazuo

1997 New Historical Perspective on Transition from Jomon to Yayoi. Tokyo: Kadokawa Shoten. (J)

HONG, WON-TACK

2006 Korea and Japan in East Asian History. Seoul: Kudara International.

HUdSON, M. J.

1990 From Toro to Yoshinogari, in Hoabinian, Jomon, Yayoi, Early Korean States: 63-112, ed. G. L. Barnes. Oxford: Oxbow Press.

1999 Ruins of Identity: Ethnogenesis in the Japanese Islands. Honolulu: University of Hawai'i Press.

IM, НYO-JAE

1978 Hunam-ni Dwelling Site No. 4. Seoul: Seoul National University Museum. (K)

Inoue, Mitsuo

1991 Immigrants and Heiankyo, in Ancient Gozoku and Korea: 81-130, ed. Kyoto Cultural Museum. Tokyo: Shin Jinbutsu Oraisha. (J)

Itatsuke City Education Committee, ed.

1995 Itatsuke Archaeological Site. Fukuoka City Buried Cultural Property Research Report No. 439. Fukuoka: Fukuoka City Education Committee. (J)

IwANAGa, Syozo

1991 Arrival of bronze weapons and the beginning of their local production, in The Archaeology of Japan-Korea Interaction: 114-119, ed. Fujio Oda and Byeong-sam Han. Tokyo: Rokuko. (J)

Japan Archaeological Association, ed.

1999 Origin and Development of Rice Cultivation in Japan. Tokyo: Gakuseisha. (J)

JeOn, YeOng-Rae

1986 Diffusion route of Japanese rice cultivation: A critique on An Zhi-Min's essay, "Influence of the prehistoric culture of the lower reaches of the Yangtze River on the Japanese archipelago," in Ethnos in Asia No. 30:107-117, ed. Naoichi Kokubu. Shimonoseki and Tokyo: Shinnihon Kyoiku Tosho. (J)

1987 Lithic implements of Korea and Japan compared, in Hanguksaron 17:131-262, ed. Guksa Pyeonchan Wiweonhoe. Seoul: National Institute of Korean History. (K)

JeONG, Jing-Weon, AND In-Soo Ha

1998 Cultural Exchanges during the Neolithic between Korea's Southern Coast and the Kyushu Region. Busan: Busan University. (K)

Jeong, Jing-Weon, ANd Kyeong-Cheol Shin

1984 A brief consideration on ancient Korean body armor and helmets, in Essays in Honor of Dr. Yun Mu-byeong's 60th Birthday: 289-297, ed. Dr. Yun Mu-byeong's 60th Birthday Publication Committee. Seoul: Tongcheon Munhwasa. (K)

JEONG, UI-DO

2000 Moat-encircled sites, in Jinju Namkang Archaeological Sites and Ancient Japan: 97-137, ed. Kaya Culture Research Institute. Kimhae: Inje University. (K)

Jinju National Museum

2002 Bronze Age Daepyeong and Its People. Jinju: Jinju National Museum. (K)

Kadowaki, TeIJI

1973 Origin of the Soga clan, in Japanese Culture and Korea: 79-91, ed. Chosen Bunkasha. Tokyo: Shin Jinbutsu Oraisha. (J)

1991 The Soga clan and the immigrants, in Ancient Gozoku and Korea: 169-212, ed. Kyoto Cultural Museum. Tokyo: Shin Jinbutsu Oraisha. (J)

Kamada, Motokazu

1986 National unification by Ohokimi (the Great King), in Struggle for King's Power: 41-91, ed. Toshio Kishi. Tokyo: Chuo Koronsha. (J) 
KAMEDA, SHuichi

2000 Iron and Immigrants. Fukuoka University Research Reports No. 240:165-184. Fukuoka: Fukuoka University. (J)

2003a Archaeology of immigrants, in Nanakuma Shigaku No. 4: 1-14, ed. Nanakuma Shigakukai. Fukuoka: Nanakuma Shigaku Association. (J)

2003b Immigrants in Michinoku, in Incorporation and Development of Immigrant Culture in the Togoku during the Kofun Period: 55-65, ed. Senshu Daigaku Bungakubu. Tokyo: Senshu University. ( $\mathrm{J}$ )

2004a Immigrants and the production of metallurgical implements, in Multiple Approaches in the Study of Iron Culture: 75-94, ed. Tekki Bunka Kenkyukai. Asaka: Tekki Bunka Kenkyukai. $(\mathrm{J})$

2004b Early iron nails and braces in Japan, in The Fiftieth Anniversary Volume of the Society of Archaeological Studies: 29-38, ed. Kokogaku Kenkyukai. Okayama: Kokogaku Kenkyukai. ( J)

2005 Archaeological criteria for identifying immigrants in various regions, in Incorporation and Development of Immigrant Culture in Kyushu: 1-16, ed. 8th Research Executive Committee on Kyushu Area Zempo Koen Tombs. Fukuoka: 8th Research Executive Committee on Kyushu Area Zempo Koen Tombs. (J)

KANASEKI, Hiroshi

1986 The evidence of social change between the Early and Middle Yayoi, in Windows on the Japanese Past: Studies in Archaeology and Prehistory: 317-334, ed. R. Pearson. Ann Arbor: University of Michigan Center for Japanese Studies.

Kanaseki, Hiroshi, and Osaka Yayoi Culture Museum, ed.

1995 Establishment of Yayoi Culture: "Jomon People" Were the Main Actors in the Great Transformation. Tokyo: Kadokawa Shoten. (J)

Karatsu City Education Committee

1993 Karatsu Matsurokan: The Nabatake Site. Karatsu City, Japan: Karatsu City Education Committee. (J)

Kashihara Archaeological Research Institute Museum

1999 Archaeology of Yamato., Kashihara: Kashihara Archaeological Research Institute Museum. (J)

KaTAOKA, KojI

1999 The Toraijin Pottery and Bronzes in the Yayoi Period. Tokyo: Yuzankaku. (J)

KaWAKAMI, KuniHIRO

2000 Zempo koen tombs and corridor tombs in Japan. Baekje Yeongu 31:93-101, ed. (K)

Kim, JEONG-HaK

1972 The Prehistory of Korea. Trans. and ed. R. J. Pearson and K. Pearson, 1978. Honolulu: University of Hawai'i Press.

KIM, KIL-SHIK

1994 A comprehensive analysis of Songguk-ni site excavations, in Archaeology of Village Settlements: 177-193, ed. Hanguk Gogohakhoe. Seoul: Korean Archaeological Society. (K)

Kim, KyU-HyeOK, AND JaE-Jin Kim

2001 Analyses of logs used for irrigation ditches at Gwanchang-ni, in Gwanchang-ni Site: 525550, ed, Hong-jong Lee, Weon-pyo Kang, and Joon-ho Son. Jochiweon: Korea University Buried Culture Research Center. (K)

Kim, Seung-OK

2001 Songguk-ni burial systems in the Gum River basin in light of cist, slab-covered pit graves, and jar burials. Journal of the Korean Archaeological Society $45: 45-74$. (K)

Kim, Tae-Shik, and Kye-Hyeon Song

2003 Diffusion of Korean horse riding culture to Japan, in Korea's Horse-riders Nation Theories: 276-302, ed. Tae-shik Kim and Kye-Hyeon Song. Seoul: Korean Equestrian Association Museum. (K)

KIM, WEON-YONG

1984 Introduction to Korean Archaeology. Seoul: Ilchisa. (K) 
Kim, Yong-Kan, and Kwang-Jun SEOK

1984 Research on Namgyeong Site. Pyeongyang: Kwahak Baekkwa Sajeon. (K)

KitANO, KoHEI

1989 Connections between sue ware and iron production in Kofun period, in International Exchanges of Toshitsu Pottery: 105-123, ed. Otani Joshi Daigaku Shiryokan. Tokyo: Kashi Shobo. (J)

Komoto, MaSAyuki

1997 Rice, iron, and mortuaries, in Jomon and Yayoi: 104-110, ed. Organizational Committee for the 11th Open Symposium on Higher Education and Science. Tokyo: Kuba Pro. $(J)$

KONDO, YOSHIRO

2005 Thoughts on the Origin of Zempo Koen Tombs. Tokyo: Aoki Shoten. (J)

KOYAMADA, KOICHI

1991 Development of ancient Kawachi and immigrants, in Ancient Kawachi and Baekje: 94-97, ed. Hirakata Rekishi Forum Jikko Iinkai. Hirakata: Daikoro Co. (J)

2003 Public works engineering of Baekje, in Ancient East Asia and Baekje: 371-375, ed. Baekje Yeonguso. Seoul: Seokyeong.

KWEON, O-YEONG

1997 Ancient state and iron, in History of Iron: 112-115, ed. Cheongju National Museum. Cheongju: Cheongju National Museum. (K)

Kyoto Cultural Museum

1989 The People Who Crossed the Sea and Their Culture. Kyoto: Kyoto Cultural Museum. (Japanese and English)

Kyushu Historical Resources Center

1980 Bronze Weapons. Fukuoka: Kyushu Historical Resources Center. (J)

LEDYARD, G. K.

1975 Galloping along with the horse riders: Looking for the founders of Japan. Journal of Japanese Studies 1(2) : 217-254.

Lee, Cheong-Kyu

1988 Development of Mumun Pottery and the position of Kongyeol-mun Pottery in southern Korea. Journal of the Ancient Korean Historical Society 1:37-92. (K)

1999 Multi-knobbed bronze mirrors and their role as burial goods. Journal of the Korean Archaeological Society 40:57-87. (K)

LEE, DONG-Ju

2000 The Neolithic culture of the Namkang region and the Japanese archipelago, in Jinju Namkang Site and Ancient Japan: 35-96, ed. Kaya Munhwa Yeonguso. Kimhae: Inje University. (K)

LEE, HYEON-SEOK

1999 Okhyeon site at Ulsan Mugeo-dong, in Bronze Age Residences and Villages of Ulsan: 65, ed. Ulsan University Museum. Ulsan: Ulsan University. (K)

LEE, JONG-CHEOL

2000 A Study of Songguk-ni Settlements in Southern Korea. M.A. thesis. Jeonbook University, Jeonju. (K)

LEE, KEON-MU

1994 Characteristics of Korean bronze culture: Its origin, in Bronze Culture of East Asia: 23-67, ed. Munhwajae Yeonguso. Seoul: National Cultural Property Research Institute of Korea. (K)

1997 Transition from bronzes to iron, in History of Iron: 89-91, ed. Cheongju National Museum. Cheongju: Cheongju National Museum. (K)

LeE, KeUn-U

1994 Daegok-ni settlement site, in Archaeology of Village Settlement: 136-153, ed. Hanguk Gogohakhoe. Seoul: Korean Archaeological Society. (K)

LEE, KI-BAEK

1996 A New, History of Korea. Seoul: Ilchogak. (K) 
LEE, KI-TONG

1996 A Study of Baekje History. Seoul: Ilchogak. (K)

LeE, NAM-SEOK

1992 Tombs with a corridor-style side entrance of early Baekje and their origin, in Seonsa wa Godae: 75-113, ed. Hanguk Godaehakhoe. Seoul: Korean Ancient Period Studies Society. (K)

1995 Study of Baekje Stone Chamber Tombs. Seoul: Hakyeon Munhwasa. (K)

Lee, NAM-Seok, Hoon LeE, AND Hyeon-SoOK Lee

1998 Baekseok-dong Site. Gongju: Gongju University Museum. (K)

LEE, SANG-KIL

2000 The characteristics and significance of bronze burials. Journal of the Korean Archaeological Society $42: 23-55$. (K)

LEe, SeOng-Ju

1991 Types, genealogy, chronology, and production system of protohistoric pottery, in Hanguk Godae Nonchong 2: 251-258, ed. Hanguk Godaesahoe Yeonguso. Seoul: Karakguk Sajeok Gaebal Yeonguweon. (K)

1998 Consideration on conceptualization of Korean iron age, in Iron Age of East Asia: 45-79, ed. Munhwajae Yeonguso. Seoul: National Cultural Property Research Institute of Korea. (K)

LEE, YeONG-CHeOL

2002 Periodization of 3rd-5th Century A.D. Settlements in the Honam Region (II). Research Essays No. 2:48, ed. Honam Munhwajae Yeonguso. Gwangju: Honam Cultural Research Institute. (K)

LEE, YEONG-HOON

1997 Iron production facilities at Jincheon Seokjang-ni, in History of Iron: 101-105, ed. Cheongju National Museum. Cheongju: Cheongju National Museum. (K)

LEE, YeONG-MOON

1993 A study of the Dolmen Society in Jeonnam Province. Ph.D. diss. Hanguk Kyoweon University, Seoul. (K)

1998 Korean bipa-shaped bronze dagger culture. Journal of Korean Archaeology 38:63-104. (K)

2002 A Study of Korean Dolmen Society. Seoul: Hakyeon Munhwasa. (K)

Matsushida, TAKayuki

1997 The Yayoi people, in Jomon and Yayoi: 98-99, ed. Organizational Committee for the 11 th Open Symposium on Higher Education and Science. Tokyo: Kuba Pro. (J)

Miyamoto, Choniro

1996 Settlements of Ancient Japan. Tokyo: Chuobijutsu Koron Shuppan. (J)

Mizuno, Suke

1975 Critical views on horse-riders' theory, in Essays on Horse-Riders' Conquest Theory: 319321. Tokyo: Yamato Shobo. (J)

Mokp'o National University Museum

1996 Ancient Burials of the Jeonnam Region. Mokp'o: Mokp'o National University. (K)

2003 Report on Excavations of Joongrang Site, Hampyeong. Mokp'o: Mokp'o National University. $(\mathrm{K})$

MORI, KOICHI

2001 Keidai dynasty and Baekje, in Ancient Kawachi and Baekje: 130-133, ed. Hirakata Rekishi Forum Jikko Iinkai. Hirakata: Daikoro Co. (J)

Mori, Tejjiro

1985 Rice, Bronze, and Iron. Tokyo: Nihon Shoseki Kabushiki Kaisha. (J)

Murakami, Yasuyuki

1998 Iron implements of the Yayoi period, in Iron Culture of East Asia: 83-92, ed. Muhwajae Yeonguso. Seoul: National Cultural Property Research Institute of Korea. (Japanese, Korean, and English)

Nakamura, Shintaro

1981 Two Thousand Years of Japan and Korea. Tokyo: Toho Shuppan. (J) 
NAKANO, KENSHI

1987 Songguk-ni Settlement. Tokyo: Dohosha Shuppan. (J)

NAOKI, KOJIRO

1992 Concerning the Kawachi political power, in Large Kofun and Kaya Culture: 140, ed. Hatsushige Otsuka et al. Tokyo: Kadokawa Shoten. $(\mathrm{J})$

National Museum of Japanese History

2004 The Origin of Farming in the Yayoi Period and East Asia. Chiba: National Museum of Japanese History. (Japanese and English)

National Museum of Korea

1979 Songguk-ni I: Text. Seoul: National Museum of Korea. (K)

1993 The Pottery of Prehistoric and Protohistoric Korea. Seoul: National Museum of Korea. (K)

1997 Korean Ancient Pottery. Seoul: National Museum of Korea. (K)

National Museum of Korea and Gwangju National Museum

1992 Bronze Culture of Korea. Seoul and Gwangju: National Museum. (K)

NeLSON, SARAH

1993 The Archaeology of Korea. Cambridge: Cambridge University Press.

Nishitani, TADASHI

1989 Yoshinogari and Korea, in Various Issues in Mahan Cultural Research: 127-132, ed. MahanBaekje Munhwa Yeonguso. Iri: Weonkwang University. (J and K)

1990 Ancient Korea and Japan. Tokyo: Meicho Shuppan. (J)

1991 Ancient Japan and Korea in light of archaeology, in Ancient Gozoku and Korea: 131-169, ed. Kyoto Cultural Museum. Tokyo: Shin Jinbutsu Oraisha. (J)

1997 Comprehensive Studies of Dolmens in East Asia. Fukuoka: Kyushu University Archaeological Research Institute. (J)

2001 Primitive agriculture of Japan and its relations to Korea, in Origin of Korea's Ancient Rice Agriculture: 261-263, ed. Hyo-jae Im. Seoul: Hakyeon Munhwasa. (J)

2004 Origin of the Yayoi period in light of archaeology, in Ancient History Illuminated by Science: $82-87$, ed. Masaaki Sawada. Tokyo: Kuba Pro. (J)

OdA, Fujio

1986 Emergence of Yayoi Culture in Northern Kyushu. Kyushu Historical Research Institute Publication 31:143-145. Fukuoka: Kyushu University. (J)

Oda, Fujio, And ByeOng-Sam Han, Ed.

1991 Archaeology of Japan-Korea Relations: The Yayoi Period. Tokyo: Rokko Shuppan. (K and J)

Osaka Chikatsuasuka Museum

2004 Imakino Tehito: Kofun and the Immigrants in Asuka. Osaka: Osaka Chikatsuasuka Museum. (J)

Osaka Yayoi Culture Museum, ed.

1999 The Appearance of People from Overseas: The People Who Opened the Door of Yayoi Culture. Osaka: Osaka Yayoi Culture Museum. (J)

2004 Yamato Kings' Pourer and Immigrants. Osaka: Osaka Yayoi Culture Museum. (J)

2005 Yayoi Frontier in the Tokai Region. Osaka: Osaka Yayoi Culture Museum. (J)

Otsuka, Hatsushige

1996 Kofun culture and the role of immigrants, in Large Kofun and Kaya Culture: 50-68, ed. Hatsushige Otsuka et al. Tokyo: Kadokawa Shoten. (J)

Pohang Combined Steel Industries Technological Research Institute and Korea University

1985 Baekje Steel Production and Technological Advancement. Pohang: Pohang Combined Steel Industries Technological Research Institute and Korea University. (K)

1986 Kaya Steel Production and Technological Advancement. Pohang: Pohang Combined Steel Industries Technological Research Institute and Korea University. (K)

Reischauer, E. O.

1977 The Japanese. Cambridge, MA: Harvard University Press.

Reischauer, E. O., and J. K. Fairbank

1958 East Asia: The Great Tradition. Boston: Houghton Mifflin Co. 
RHEE, SONG-NAI

2001 Mumun, in East Asia and Oceania, ed. P. N. Peregrine and M. Ember. Vol. 3 of Encyclopedia of Prehistory: 256-271, New York and London: Kluwer Academic/Plenum Publishers.

Rhee, Song-Nai, and Mong-Lyong Choi

1992 Emergence of complex society in prehistoric Korea. Journal of World Prehistory 6(1):5195.

ROH, JOONG-GuK

1988 Baekje Political History. Seoul: Ilchogak. (K)

Roh, TAE-CHEON

1998 Steel production technology (chogang gisul) in 4th-century Baekje. Baekje Yeongu 28:4963. (K)

SADAMORI, Hideo

1997 Early sue ware and dojil pottery of the Korea Peninsula, in Ancient Korean Pottery: 167176, ed. National Museum of Korea. Seoul: National Museum of Korea. (K)

Saga Prefecture Kyoiku Iinkai, ed.

1990 A Moated Settlement: The Archaeological Site of Yoshinogari. Tokyo: Yoshikawa Kobunkan. (J)

SAHARA, MAKoto

1986 Horse riders did not found the [Yamato] royal dynasty, in Ancient History of Japan, vol. 1:127-162, ed. Makoto Sahara. Tokyo: Shueisha. (J)

Sahara, Makoto, and Hiroshi Kanaseki

1981 Beginning of Rice Cultivation. Tokyo: Kodansha. (J)

SAKAI, KYOJI

2004 The Beginning of the Sue Ware Production. National Historical and Ethno. Museum Report 110. National Historical and Ethno. Museum of Japan. (J)

Sakurai City Buried Cultural Property Center

2005 Continental Culture and the Immigrants: The Activities of the Immigrants in the Southern Nara Basin. Sakurai: Sakurai City Buried Cultural Property Center. (J)

SANSOM, G. B.

1962 Japan: A Short Cultural History. Englewood Cliffs, NJ: Prentice-Hall, Inc.

SEONG, JeONG-Yong

1997 Bronze Age sites at Shindae-dong and Birae-dong in Daejeon, in Various Issues in Honam Archaeology: 205-236, ed. Hanguk Gogohakhoe. Seoul: Korean Archaeological Society. (K)

Seoul Museum of History, ed.

2002 Poongnap Earthen Fortress. Seoul: Seoul Museum of History. (K)

SHIM, Bong-KeUN

1999 Emergence of Yayoi Culture from the Korean Perspective. Seoul: Hakyeon Munhwasa. (K)

SнIмоjo, NoвuYuki

1989 Birth of Yayoi Farming Villages. Tokyo: Kodansha. (J)

SHIN, HyeON-DONG

1993 A study of ancient dwellings of Korea and Japan, in Prehistoric and Ancient Settlements and Their Influence on Japan: 48-53, ed. H. D. Shin. Tokyo: Yuzankaku. (J)

Shin, KyeOng-CheOl

2000 Ancient iron body armor and helmets of the Yeongnam area, in Haksan Kim-Jeong-hak Baksa Songsu Ginyeom Nonchong: Hanguk Godaesa wa Gogohak: 261-276, ed. Publication Committee for a Festschrift in Honor of Dr. Kim-Jeong-hak. Seoul: Hakyeon Munhwasa. (K)

Shin, Kyeong-Cheol, And Jae-Woo Kim

1988 Kimhae Daeseong-dong Tumuli I. Busan: Kyeongseong University Museum. (K)

2000 Kimhae Daeseong-dong Tumuli II. Busan: Kyeongseong University Museum. (K)

SHINTAKU, NoBUhisa

1993 The oldest rice-farming village: Fukuoka Etsuji site. Archaeology Quarterly 45. Tokyo: Yuzankaku. (J) 
Shirai, Katsuya

2001 Baekje-Mahan pottery and Wa, in Ancient Kawachi and Baekje: 81-82, ed. Hirakata Rekishi Forum Jikko Iinkai. Hirakata: Daikoro Co. (J)

ShIRAISHI, SHIN'ICHIRo

2004 Immigrants and their civilizing of Wa, in Imaki no Tehito: 7-13, ed. Osaka Chikakuasuka Museum staff. Osaka: Osaka Chikakuasuka Museum. (J)

So, JAE-YUN

2004 A study on the changes of Baekje roof-tiled buildings. Journal of the Korean Ancient Historical Society $45: 49-70$. (K)

SONG, JEONG-SHIK

2003 Study of Jongjang Pangap (Body Armors of Vertical Iron Plates). M.A. thesis. Busan, Busan University.

SONG, KYE-HYEON

1995 Ancient iron production in the lower Nakdong River basin, in Iron of Kaya States: 129151, ed. Kaya Munhwa Yeonguso. Kimhae: Inje University. (K)

1997 Iron culture of the three kingdoms, in History of Iron in Korea: 96-100, ed. Cheongju National Museum staff. Cheongju: Cheongju National Museum. (K)

SONG, MAN-YEONG

2000 Changes in warfare in the central region during the Proto-Three Kingdoms and Early Baekje periods. Journal of the Korean Archaeological Society 43:139-170. (K)

2001 Settlement patterns and their changes during emergence of agriculture in southern Korea, in Emergence of Ancient Agriculture in Korea: 75-110. Seoul: Korean Archaeological Society. $(\mathrm{K})$

SPACAM (Shiga Prefecture Azuchi Castle Archaeological Museum)

2001 Migrations from Korea: Ancient State Formation and the Immigrants. Shiga Prefectural Azuchi Castle Archaeological Museum. (J)

Suematsu, Yasukazu

1949 Rise and Fall of Mimana. Tokyo: Ooyashima Shuppan. (Reprinted in 1956 and 1961 by Yoshikawa Kobunkan.) (J)

Suzuki, Yasutami

1995 Kaya (Byunhan) iron and Wa, in Iron of Kaya States: 35-46, ed. Kaya Munhwa Yeonguso. Kimhae: Inje University. ( $\mathrm{J}$ and $\mathrm{K}$ )

TAKAKU, KENJI

1995 Study of Nangnang Burials. Seoul: Hakyeon Munhwasa. (K with English summary)

TAKAKURA, HIROAKI

1995 Diffusion of rice cultivation from the Korea Peninsula, in Origins of Rice Cultivation in East Asia and Ancient Rice Agriculture (in Japan): ed. Kikuo Wasano. Saga City: Saga University Department of Agriculture. (J)

TAKesue, Junichi

1985 Locally made bronze weapons, in Rice, Bronze, and Iron: 129-147, ed. T. Mori. Tokyo: Nihon Shoseki Kabushiki Kaisha. (J)

1998 Kaya and ancient Japan in light of the pottery, in Essays on Kaya History 1: Kaya and Ancient Japan: 93-126. Kimhae: Kimhae City Office. (K)

2001 Yayoi settlements in northern Kyushu, in The Yayoi Period Settlements: 102-117, ed. Hiroshi Kanaseki. Osaka: OsakaYayoi Culture Museum. (J)

2002 Emergence and development of Kuni in northern Kyushu. Yeongnam Journal of Archaeology $30: 25-28$. (K)

TANAKA, KYOMI

2004 The immigrants in Setsu and Kawachi, in Imaki no Tehito. Osaka: Osaka Chikakuasuka Museum. (J)

TANAKA, RYOJI

1997 Regarding Toraijin: A roundtable discussion, in Jomon and Yayoi: 102, ed. Organizational Committee for the 11th Open Symposium on Higher Education and Science. Tokyo: Kuba Pro. (J)

TANAKA, TOSHIAKI

1992 Rise and Fall of Dae Kaya Confederation and "Mimana." Tokyo: Yoshikawa Kobunkan. (J) 
2001 Relationship between Baekje and Wa, in Ancient Kawachi and Baekje: 2-23, ed. Hirakata Rekishi Forum Jikko Iinkai. Hirakata: Daikoro. (J)

TERASAWA, KaORU

2001 Villages with encircling moat, in The Yayoi Period Settlements: 26-28, ed. Hiroshi Kanaseki. Tokyo: Gakuseisha. (J)

2004 State formation in the Japanese archipelago, in From Wa kuni to Nihon: 26-43, ed. Yasutami Suzuki. Tokyo: Gakuseisha. (J)

Ueda, MASAaki

1991 Korean immigrants in [Japan's] ancient history, in Ancient Gozoku and Korea: 61-66, ed. Kyoto Cultural Museum. Tokyo: Shinjinbutsu Oraisha. (J)

VARGO, L.

1982 Social and Economic Conditions for the Formation of the Early Japanese State. Stockholm: Stockholm University.

Wada, Seigo

1986 Political interpretations of stone coffin production in protohistoric Japan, in Windows on the Japanese Past: Studies in Archaeology and Prehistory: 349-374, ed. R. Pearson. Ann Arbor: University of Michigan Center for Japanese Studies.

Wasano, Kikuo

1995 Rice grains of ancient Asia and the origin of rice cultivation, in Origins of Rice Cultivation in East Asia and Ancient Rice Agriculture (in Japan): 3-52, ed. Kikuo Wasano. Saga City: Saga University Department of Agriculture. (J)

Weonkwang University

2000 Iksan Yeongdeung-dong Site. Iri: Weonkwang University. (K)

YAMAO, YUKIHISA

1977 Formation of the Japanese State. Tokyo: Iwanami Shoten. (J)

1989 Ancient Japan-Korea Relations. Tokyo: Hanawa Shobo. (J)

1997 Regarding Mimana Nihonfu, in Kaya and Ancient Japan: 27-39. Kimhae: Kimhae City Office. (K)

1998 Iwaii's war in light of ancient historical records, in Iwaii's War: 81-134, ed. Enjo Tamura, Fujio Oda, and Yukihisa Yamao. Tokyo: Yamato Shobo. (J)

YAMAZAKI, J.

1991 Origin and development of rice cultivation in Kyushu, in Origin and Development of Rice Cultivation in Japan: 21-26, ed. Japan Archaeological Association (Nihon Kokogakukai). Tokyo: Gakuseisha. (J)

YAN, WEN-MING

1991 Origin of Chinese rice cultivation and its early diffusion, in Origin and Development of Rice Cultivation in Japan: 9-16, ed. Japan Archaeological Association (Nihon Kokogakukai). Tokyo: Gakuseisha. (J)

Yanagita, Yasuo

1987 Locally made bronze implements and their associated materials in northern Kyushu. Kobunka Danso 17:17-26. (J)

1992 Japanese culture observed in the protohistoric Korea Peninsula, in Cultural Exchanges between Korea and Japan during the Protohistoric and Three-Kingdoms Periods: 27-40, ed. Hanguk Sangosa Hakhoe. Seoul: Korean Ancient Historical Society. (J)

Yeongnam Archaeology Association

1991 The first excavation report on the Gyeongju Hwangseong-dong site. Yeongnam Archaeology 8. Busan: Yeongnam Archaeological Association. (K)

YosHida, SHO

1975 Ancient State Formation. Iwanami Japanese History Lecture Series. Tokyo: Iwanami Shoten. (J)

Yoshi'I, Hideo

2001 Adoption of Baekje tombs and its ramifications, in Ancient Kawachi and Baekje: 104-117, ed. Hirakata Rekishi Forum Jikko I'inkai. Hirakata: Daikoro Co. (J)

YoShimura, KAZUAKI

2000 Iron armor and weapons in protohistoric Japan, in Clashes of Iron: Arms, Weaponry, and Warfare in Early East Asian States: 104-111, ed. G. L. Barnes. Leiden: Brill. 


\section{ABSTRACT}

This is a study of Korean contributions to cultural changes in ancient Japan as it developed agriculture and increasing social complexity and finally formed the Yamato state over the course of a thousand years, between 400 B.C. and A.D. 600 . Central to this study are three broad themes, supported primarily by archaeology but importantly informed by historical texts. First, key cultural features and technologies that were essential to increasing social complexity in Yayoi period Japan and to formation of a centralized state in the sixth century A.D. entered the archipelago directly from the Korea Peninsula. Second, a dominant factor behind the infusion of Korean cultural features was the movement, in several waves, of peninsula residents into the Japanese archipelago. While trade moved peninsula goods to the archipelago all throughout the formative period, Korean technologies, skills, ideologies, and cultural systems moved with people, including permanent immigrants, temporary residents, and official envoys. The Korean immigrants in particular were impelled initially by explosive population growth in Korea fueled by the spread of agriculture there and later by increasingly tumultuous political and military events that unfolded in the peninsula as rival polities contended for power during several hundred years of war. Third, a number of Korean immigrants emerged as powerful technocrats and political functionaries during the Kofun period, providing important organizational experience and service to the Yamato court during the process of state formation in Japan. KeYwords: Korea, Japan, China, Mumun, Songguk-ni, Jomon, Yayoi, Kofun, Koguryo, Baekje, Kaya, Yamato, Buddhism, Soga, Muryeong, Shotoku. 